\title{
La construcción de significados de un destino turístico a partir de la experiencia de los visitantes de crucero. El caso de Ushuaia
}

\section{Construction of tourist destination meanings based on cruise visitors' experience. The case of Ushuaia}

\author{
Carolina Cohen \\ Licenciada en Geografía. Becaria Doctoral del Consejo Nacional de Investigaciones Científicas y Técnicas CONICET. Instituto de Desarrollo \\ Económico e Innovación. Universidad Nacional de Tierra del Fuego, Antártida e Islas del Atlántico Sur UNTDF. Yrigoyen 879, (9410) Ushuaia, \\ Tierra del Fuego, Argentina, ccohen@untdf.edu.ar \\ Marisol Vereda \\ Doctora en Geografía. Instituto de Desarrollo Económico e Innovación. Universidad Nacional de Tierra del Fuego, Antártida e Islas del Atlántico Sur \\ UNTDF. Yrigoyen 879, (9410) Ushuaia, Tierra del Fuego, Argentina, mvereda@untdf.edu.ar
}

Recibido: 8 de noviembre 2019 || Aprobado: 23 de abril 2020

Resumen

Ushuaia está posicionada como un interesante destino para las líneas de crucero. Este estudio se enfoca en la experiencia de los cruceristas que visitan la ciudad como parte de un viaje más extenso por América del Sur. La metodología comprende un enfoque cuantitativo a partir de encuestas que fueron realizadas durante las temporadas de verano 2015/2016, 2016/2017 y 2017/2018. Los resultados muestran que las motivaciones están relacionadas con la posibilidad de conocer Patagonia, mientras que Ushuaia es altamente valorada por su paisaje y la idea de 'fin del mundo', alcanzando un alto grado de satisfacción en la experiencia. Estos resultados brindan a los tomadores de decisiones herramientas sobre cómo optimizar los productos y servicios para satisfacer las necesidades de los visitantes, posicionar mejor al destino y lograr que los beneficios derivados de la actividad redunden en la localidad.

Palabras clave: Cruceristas; Motivación; Percepción; Satisfacción

Abstract

Ushuaia has ranked as a very interesting destination for cruise liners. This study focuses on the experience of cruise passengers who visit Ushuaia as part of a longer voyage in South America or even a more extensive itinerary. A survey was carried out during the 2015/2016, 2016/2017 and $2017 / 2018$ summer seasons. Results show main motivations are especially related to discovering Patagonia, while Ushuaia is highly appraised for its landscape and the idea of the 'end of the world'. Besides, visitors achieve a high level of satisfaction. These findings provide decision-makers in the local tourist sector with ideas on how to improve products and services in order not only to cater to but also benefit from the cruise industry by meeting visitors' needs.

Key words: Cruise passengers; Motivations; Perceptions; Satisfaction

Cita sugerida: Cohen, C. y Vereda, M. (2020). La construcción de significados de un destino turístico a partir de la experiencia de los visitantes de crucero. El caso de Ushuaia. Estudios Socioterritoriales. Revista de Geografía, (27), 049. DOI: //https://doi.org/10.37.838/unicen/est. 27-049 


\section{INTRODUCCIÓN}

Ruiz Quesada y Parada Gutiérrez (2013) en un informe que realizaron para la Organización Mundial del Turismo (OMT) proponen a la modalidad de cruceros como

aquella en la que el cliente embarca en un puerto con un itinerario previamente definido o no, con el objetivo de disfrutar de unas vacaciones marítimas diferentes a las tradicionales en tierra. Los clientes de esta modalidad por sus características y expectativas son denominados "cruceristas" y son excursionistas por naturaleza. (p. 50)

Durante mucho tiempo se catalogó como excepcional pero esta percepción cambia a partir del siglo XIX con el surgimiento de la era de barcos a vapor ${ }^{1}$, donde comienza una etapa en la navegación marítima relacionada con el transporte de pasajeros por rutas oceánicas que contribuye a cambiar las formas de percibir la relación espacio-tiempo, pero, además, en la posibilidad de integración de los territorios. Así el transporte marítimo se constituyó en un medio de comunicación de gran importancia que irá adquiriendo cada vez más relevancia hasta consolidarse como un segmento específico de la práctica turística correspondiente al turismo de cruceros ${ }^{2}$.

La transición no fue fácil, implicó llevar a cabo importantes inversiones, afirma Martínez (2012), buscar nuevos mercados para rentabilizar los gastos, expandir el patrón geográfico unidireccional Europa-América y diversificarse

1 Dos buques se desatacan en este período. El Sirius que en 1838 realizó la primera travesía del Atlántico cruzándolo en 18 días y el Great Eastern en 1850 con 18.900 toneladas, que favoreció la consagración del transporte marítimo de pasajeros demostrando que, al triplicar la longitud del barco, solo se requiere duplicar la potencia para moverlo (Estepa Montero, 2013).

2 "Sus inicios se remontan a comienzos de los años '60 coincidiendo con la caída de la industria de los barcos transoceánicos y la introducción de los primeros viajes aéreos sin escala entre Estados Unidos y Europa" (Brida, Zapata Aguirre y Giraldo Velásquez, 2010, p. 2) por casi todos los mares. Estos cambios son pensados, como proponen Sheller y Urry (2006) como una nueva fuente de poder porque no todos los territorios son incorporados por igual, “(...) la actividad espacial en redes más complejas (...) pone a los lugares en relaciones espacio-temporales económicas, culturales y políticas que sobrepasan las fronteras de los estados" (Montañez Gómez y Delgado Mahecha, 1998 , p. 7). Esto es así porque como propone Blanco (2007), el diseño, la construcción y la utilización de una red dependen de los medios técnicos a disposición, de los contextos políticos y socio-económicos, así como de los propios intereses de los actores.

La movilidad que caracteriza al turismo de cruceros permite distinguirlo del resto de las modalidades turísticas debido a su capacidad de diversificar las zonas de operación con gran flexibilidad. Las compañías de cruceros han sabido aprovechar los factores climáticos, la estacionalidad de los destinos y sus atractivos, la cercanía a los mercados emisores y las perspectivas de crecimiento para mantener su operatividad todo el año, reflexiona Martínez (2012), aprovechando la distribución y el alcance espacial que los caracteriza. Como parte de sus estrategias competitivas y debido al aumento constante tanto de la capacidad global de sus flotas como del tamaño de los cruceros, la incorporación de nuevos puertos-destino ha producido un salto cuantitativo en la llegada de cruceristas a diversos puertos (Jensen y Daverio, 2004).

Se presenta, entonces, un mapa complejo de movilidad (Figura 1) que demanda puertos que permitan realizar el recambio de pasajeros $y$ tripulantes y el abastecimiento de diferentes insumos, como así también una serie de recursos territoriales que configuren una oferta turística atractiva para el pasajero y remunerativa para los operadores (Vereda y Jensen, 2014). 


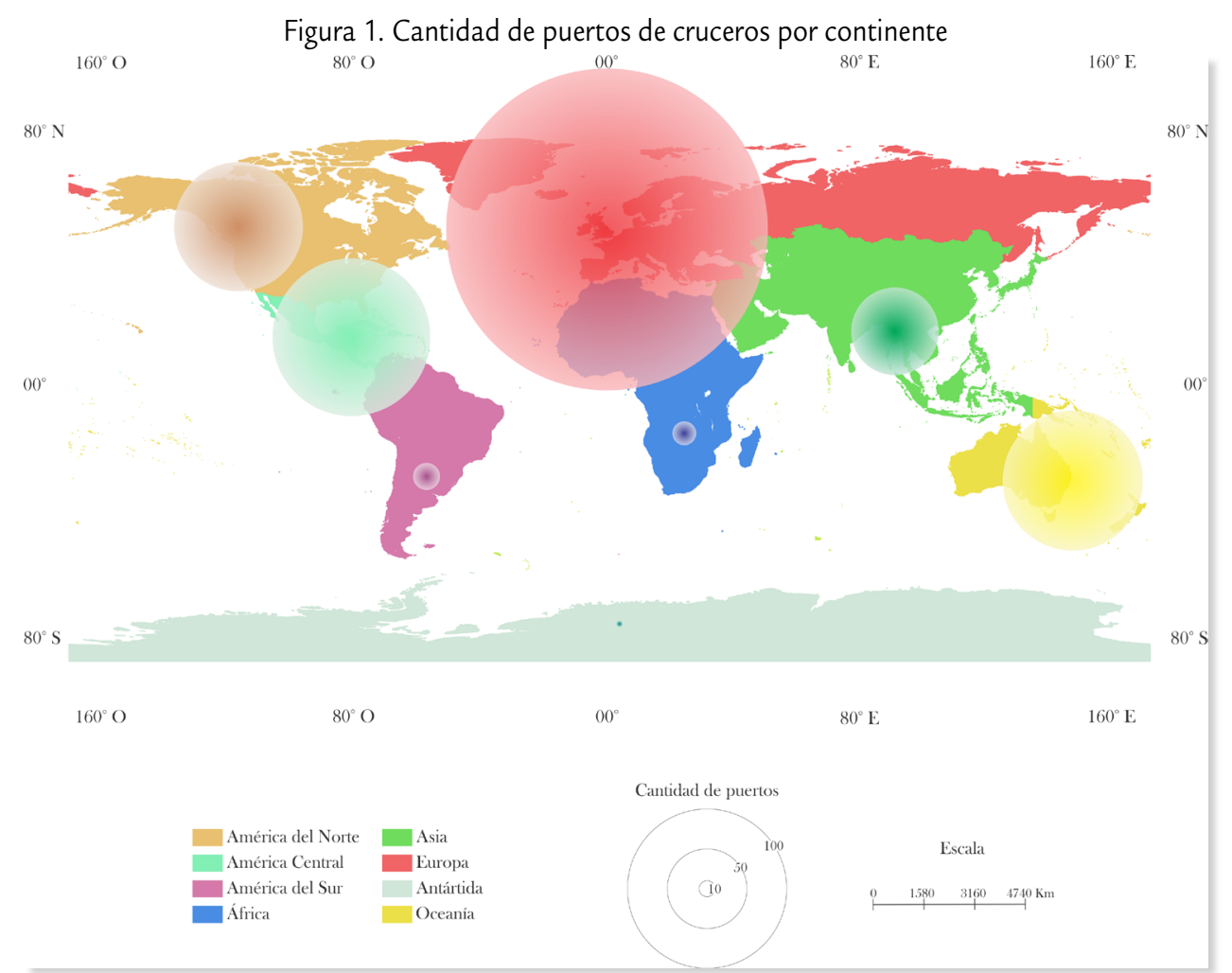

Fuente: elaboración personal con base en Butler (2008); Martínez (2012) y CLIA (2015)

En este sentido, se genera la conformación de áreas que sean geográficamente interesantes y convenientes para las compañías otorgándole a la perspectiva espacial un rol fundamental. Las mismas adquieren el carácter de regiones y si bien existe una gran diversidad de posturas en relación a este concepto, desde el Turismo de Cruceros es posible entenderlas como lo propone Paasi (1986 en Benedetti, 2011), entidades geo-históricas, funcionales y simbólicas que surgen, se transforman y desaparecen en un período de tiempo determinado $y$, que son producidas y reproducidas continuamente. En otras palabras, se trata de una construcción mental que se materializa en el Espacio Geográfico a partir de la conjunción de elementos que los distinguen y diferencian del resto.

Como expresa Santos (1986) hay una elaboración y reelaboración de sub-espacio que son resultado de una combinación de variables, y así formado extrae su especificidad. Desde el turismo de cruceros, se distinguen tres regiones que son las que determinan los circuitos.
Se denominan Primarias, Secundarias y Terciarias o Emergentes y responden al nivel de consolidación que han logrado establecer en relación a la actividad:

-Regiones Primarias: comprenden los circuitos del Mar Caribe, el Mar Mediterráneo, la Costa Pacífico de Estados Unidos, el Mar y Costa Septentrional de América del Norte y Europa y, Asia Pacífico de la mano del Sudeste Asiático, el Lejano Oriente y el Pacífico Sur. La primera ruta se destaca por una preeminencia respecto a las otras. La clave del éxito, afirma Butler (2008), radica en la magnitud de la demanda generada en América anglosajona que busca paraísos tropicales en la amplia diversidad de sus espacios insulares más próximos, el clima benigno durante todo el año y el empleo generalizado del dólar como medio de pago.

-Regiones Secundarias: Están representadas por Sudamérica, Antártida y la Costa Occidental de México. Esteve Pérez, García Sán- 
chez y Romero Gutiérrez (2016) destacan que ante el crecimiento del tráfico de cruceros las navieras han buscado nuevos puertos que permitan atender y satisfacer la demanda. El Cono Sur ha sabido incorporarse al circuito internacional de los cruceros recibiendo en la temporada veraniega noviembre-marzo una cantidad alentadora de naves de turismo y pasajeros $y$, fundamentalmente actuando como alternativa de los saturados destinos de las regiones primarias (Ghisolfo, 2001).

-Regiones Emergentes: Integradas por Medio Oriente, Mar Rojo, Golfo Arábigo, India y el Sur de África si bien han mostrado un crecimiento y dinamismo interesante, su actividad es aún muy baja, con una oferta de lujo orien- tada a los consumidores europeos.

El mapa geográfico que se desprende de esta regionalización, retrae al concepto de espacio reticulado expresado por Santos (2000) como

una construcción deliberada dispuesta a responder a los estímulos de la producción en todas sus formas, materiales e inmateriales a través de la consolidación de redes, la apuesta no es la ocupación de áreas, sino la preocupación de activar puntos y líneas, o de crear nuevas. (p. 222)

Ushuaia (Argentina), ubicada en el extremo meridional de Sudamérica, sobre la costa norte del Canal Beagle (Figura 2) se ha constituido como un destino de cruceros desde principios del siglo $X X$, cuando las compañías navieras comenzaron a ofrecer itinerarios a través de los canales fueguinos.

Figura 2. Mapa de localización de Ushuaia

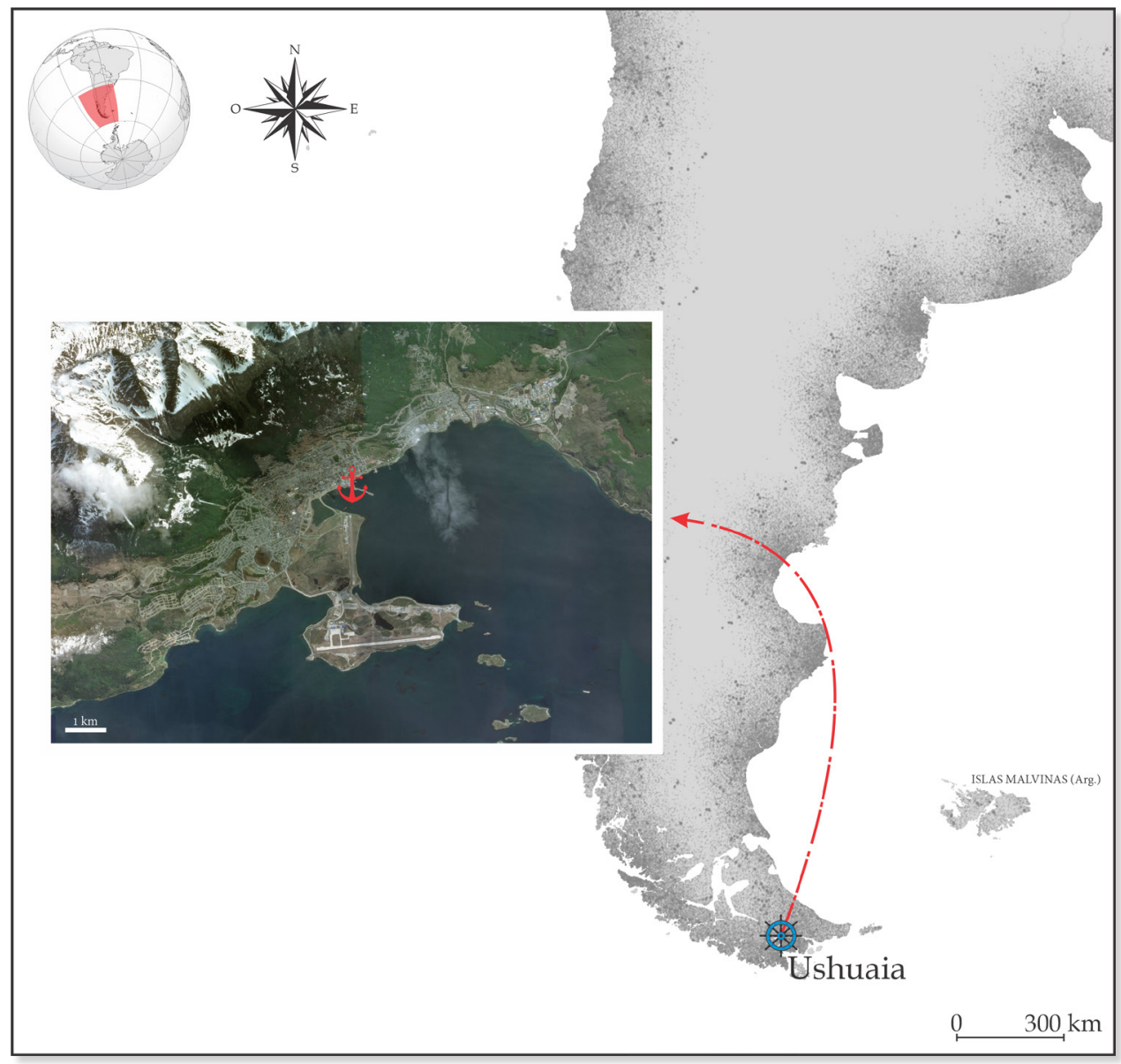

Fuente: elaboración personal con base en QGIS 3.4 y Google Earth 
Como consecuencia del desarrollo de los viajes a áreas remotas, los turistas interesados en visitar lugares relacionados con paisajes y actividades en la naturaleza encontraron en Ushuaia un destino singular, alcanzando durante la temporada alta estival (octubre-abril) 2017/2018 un total de 288.215 visitantes, de los cuales el $64,9 \%$ correspondió a arribos vía aérea y terrestre y el restante $35,1 \%$ a cruceros turísticos (InFueTur, 2018).

Las modalidades de operación de los cruceros que caracterizan a la región permiten la visita de embarcaciones que realizan entre otras rutas 'Antártida' 'Buenos Aires-Valparaíso' 'Sudamérica-Estrecho de Magallanes' y 'Canal Beagle-Cabo de hornos'. De acuerdo a la CLIA (2017, en InFueTur, 2018) los itinerarios por la Patagonia atraen viajeros en busca de lo exótico y lo aventurero, donde el deseo o motivación por conocer atracciones cultural y naturalmente ricas son un eje fundamental en el éxito que tienen estos destinos. Así, diferentes itinerarios son propuestos para la realización del recorrido en crucero por la región. Tres modalidades son claramente diferenciadas (Figura 3).

Figura 3. Comportamiento del Turismo de Cruceros en la región patagónica

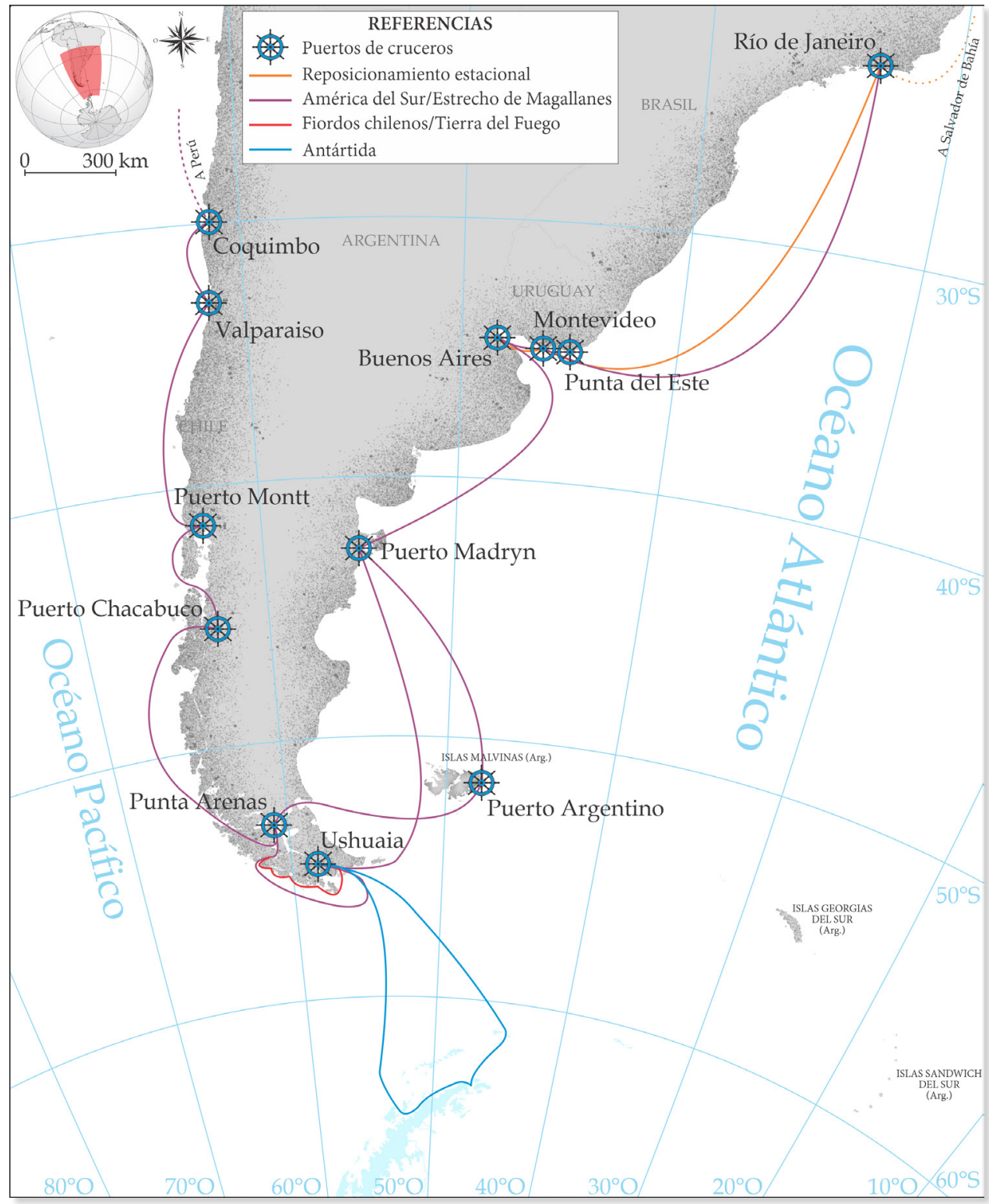

Fuente: elaboración personal con base en Martínez (2012) 
-Canales Fueguinos: Corresponden a los viajes donde Ushuaia y Punta Arenas se comportan como punto de inicio y fin del itinerario, formando una modalidad de viaje de tipo circular que brinda la posibilidad de acceder a diferentes puntos del archipiélago fueguino.

-Pendulares o del Cono Sur: Navegan los océanos Atlántico y Pacífico formando un péndulo que conecta en su recorrido a Brasil, Uruguay, Argentina y Chile. Al finalizar su viaje se realiza el recambio de pasajeros y comienza su recorrido en sentido inverso. En este tipo de itinerario se da la oportunidad de recorrer la mayor cantidad de puertos que conforma la región, brindando la posibilidad de acceder a la diversidad y multiplicidad de paisajes, cultura y costumbres que ofrece la Patagonia. En algunos casos, estos buques de gran porte se aproximan a aguas antárticas, pero solo navegan las mismas no teniendo autorización para realizar desembarcos, según la Medida 15 (2009) del sistema del Tratado Antártico.

-Viajes Antárticos: Posicionan a Ushuaia como puerto base y en menor medida como puerto de escala, inicio o fin del itinerario. Utilizan embarcaciones de tipo rompehielos o con casco reforzado y, por lo general, los itinerarios se realizan mediante buques charteados a diferentes armadoras por parte de tour operadoras y en menor medida, por líneas de cruceros. El área de destino incluye la Península Antártica y otros archipiélagos antárticos como las Islas Orcadas del Sur y Shetland del Sur, en algunos casos incorporan también las Islas Malvinas y las Islas Georgias del Sur.

La temporada inicia en noviembre-diciembre a partir del reposicionamiento de los buques que llegan del hemisferio norte, explica Martínez (2012), y se extiende hasta fines de marzo, principios de abril. Si bien, como menciona la autora, el porcentaje de buques que se concentra en la ruta patagónica es considerable- mente menor que el que se dirige hacia el norte de Sudamérica, tanto los puertos argentinos como los chilenos tienen cada vez mayor participación en esta actividad.

Dos categorías definen a los cruceristas que llegan a la ciudad. Por un lado, los antárticos que embarcan y/o desembarcan en el puerto de Ushuaia, como la puerta de entrada marítima a la Antártida más activa y, por el otro, los visitantes que llegan a la ciudad en cruceros como parte de un viaje más extenso por Sudamérica, en un itinerario que incluye otros puertos de la región. Según los datos publicados por el InFueTur (2018), a partir del relevamiento realizado por el equipo de investigación de la Universidad Nacional de Tierra del Fuego, Antártida e Islas del Atlántico Sur 3 , para la temporada 2017/2018 el $42,5 \%$ de los cruceristas corresponde al primer tipo y el $57,5 \%$ representan a los visitantes que recorren Sudamérica en un itinerario más amplio, grupo sobre el cual se focaliza este estudio. A pesar del significativo número de cruceristas que recibe la ciudad cada temporada, como parte del itinerario que conecta el Pacífico y el Atlántico a través del Canal Beagle, es escasa la atención que se ha puesto en relación con las motivaciones, precepciones y satisfacción de los visitantes de cruceros en relación con Ushuaia como destino.

La actividad de cruceros expresa la reestructuración económica global y promueve nuevas formas de territorialización, reflexiona Wood (2000). Es en el territorio donde se constituye y se define la práctica turística como una construcción social, por ello resulta de particular interés poner énfasis en la naturaleza del turismo como consumidor, productor y transformador de espacios materiales y simbólicos de una comunidad receptora (Bustos Cara, 2001). La movilidad turística de los cruceros se ve subordinada al juego de relaciones que plantea Santos (1986) en donde las variables proceden sobre todo desde centros de decisión cuyos objetivos no son necesariamente coincidentes y están situados en diversos puntos del mundo. En este

3 PIDUNTDF A 2016 y 2018. Directoras Esp. Marie Jensen y Dra. Marisol Vereda respectivamente. 
marco surgen como interrogantes ¿Qué tipo de experiencia tienen los visitantes de crucero durante su estadía en Ushuaia? ¿Qué significados le asignan al destino en función de esa experiencia vivida? Para dar respuesta a ello se propone como objetivo analizar las motivaciones, percepciones y satisfacción de los cruceristas en Ushuaia. El estudio fue realizado durante las temporadas 2015/2016, 2016/2017 y 2017/2018 a partir de encuestas realizadas luego que los cruceristas llevaran a cabo las diferentes actividades ofrecidas en el destino.

\section{MARCO TEÓRICO-CONCEPTUAL}

El espacio geográfico como resultado de una construcción social otorga una mirada y un posicionamiento socio-espacial. No se trata de un producto o de la suma de objetos, sino, como expresa Lefebvre (1976 en Lobato Corrêa, 1995), se trata del más importante de todos los instrumentos, el presupuesto de toda producción y de todo intercambio, vinculado directamente con la reproducción de las relaciones (sociales) de producción. Como plantea Pillet Capdepón (2004) su defensa hacia la condición social como elemento identificador dio paso a posicionar como principal objetivo a los procesos que determinan la diferenciación espacial. Sin embargo, plantear al espacio como producto social implica otorgarle una relación unidireccional, porque descuida la influencia del espacio sobre la propia sociedad (Rojas López y Gómez Acosta, 2010). En este marco, el reconocido investigador Santos aportó a la definición de Espacio Geográfico, desde una visión socio-espacial:

\footnotetext{
Una instancia de la sociedad, al mismo nivel que la instancia económica y la instancia cultural-ideológica (...) el espacio contiene y está contenido por las demás instancias, del mismo modo que cada una de ellas lo contiene y es por ellas contenida. La economía está en el espacio, así como el espacio está en la economía. Lo mismo ocurre con lo político-institucional. (Santos, 1986, p. 3)
}

En esta dialéctica se despeja la idea del espacio como un espejo de la sociedad y se com- prende que se trata de una co-evolución. Lobato Corrêa (1995) destaca a través de Santos (1977) que no es posible concebir una determinada formación socio-económica sin recurrir al espacio, pues el modo de producción, la formación socio-económica y el espacio son categorías interdependientes. La concepción socio-espacial permite explicitar la interrelación entre sociedad y espacio, aseverando que uno no puede existir sin el otro. "Son los procesos sociales en su dimensión espacial, como expresión directa del cambio (...) el objetivo que se propone para la geografía" (Ortega Valcárcel, 2000, p. 516).

A esta característica social Tuan (1979 en Lobato Corrêa, 1995) le incorpora los sentimientos espaciales y las ideas de un grupo o pueblo a partir de la experiencia argumentando que existen, entonces, varios tipos de espacio. En este sentido, el turismo es planteado como un importante consumidor de espacios y como tal utiliza el territorio en el sentido más amplio de la expresión, es decir, como soporte físico sumándole las condiciones sociales que le dan sentido, como productor y como agente transformador (Vereda, 2007).

Los lugares turísticos, ya no se consideran como meros contenedores de atractivos naturalizados y prexistentes, sino como ámbitos cuya condición turística deriva de procesos (Bertoncello, 2006). La dimensión territorial del espacio turístico caracteriza a una formación socio-espacial compuesta por dos tipos de espacios: el material o construido y el inmaterial basado en las imágenes y representaciones que se conforman en connotaciones mercantiles de la promoción turística sobre el espacio material (Cammarata, 2006). A partir de esta práctica social se integran distintos mecanismos de relación con el territorio.

El turismo de cruceros es planteado como una actividad dinámica y cambiante, resultado de diferentes formas de apropiación, siendo múltiples las manifestaciones que se yuxtaponen en el territorio. Sin embargo, es indiscutido que para que el mismo adquiera 
identidad real debe responder como objeto de interés, pues como asegura Callizo Soneiro (1991) si bien todos los espacios poseen condiciones que permitirían posicionarlo como potenciales turísticos, no necesariamente llegarán a serlo. La producción turística responde a un proceso de valoración, transformación y re-funcionalización del territorio que se va definiendo en relación a los intereses y acciones de los actores involucrados.

Desde este marco se reconoce el papel de los cruceristas en la construcción territorial del turismo, quienes a través de su imagen y representación pueden influir en la consecución de un destino. Conforman ese grupo de actores extraños que manifiestan su impacto de múltiples maneras "no es una mercancía, es un representante de otra sociedad, cargado de actitudes, información, subjetividad (...)" (Bustos Cara, 2001 p. 3). Caracterizar las dimensiones materiales y subjetivas que intervienen en el territorio desde la mirada del visitante permite entender qué valoraciones revisten y potencian al territorio y sobre qué aspectos deben concentrarse las localidades estudiadas para que el turismo de cruceros se establezca como una actividad con posibilidad de potenciar al máximo sus capacidades territoriales.

Al abordar un estudio desde el concepto de experiencia se realiza un análisis centrado en el interés por el sujeto. De acuerdo a Tuan (2001) la experiencia es un término que cubre los varios modos en que una persona conoce y construye una realidad. En el contexto del turismo, Cohen (1979 en Mannell e Iso-Ahola, 1987) plantean la experiencia en el sentido de la búsqueda de un centro, comparándolo con la experiencia religiosa como resultado de una peregrinación, donde la búsqueda del turista se centra en aspectos intangibles y más gratificantes que el viaje per se, que simplemente haber estado ahí. Sharpley y Stone proponen definir que

la experiencia de ser un turista, resulta no solo de una combinación particular de experiencias provistas, sino también del significado que le otorga el turista en relación con su existencia sociocultu- ral normal (la mayoría de las veces se considera en términos de la experiencia de la diferencia, la novedad o el 'otro'), y que puede estar mediado por las características del destino. $(2011,3)$

El significado que adquiere este concepto propone, como afirma Uriely (2005), a la subjetividad como constituyente y a la motivación como uno de los componentes claves para comprender la experiencia. El turismo como práctica social ofrece respuesta a necesidades y valores adquiridos en una sociedad determinada. Una vez que las necesidades y valores han sido activados y aplicados a un destino turístico, la motivación generada constituye un parámetro mayor en la generación de expectativas las que, a su vez, determinan la actuación sobre la percepción de productos y servicios como así también de experiencias (Gnoth, 1997). La motivación es un concepto que se utiliza para describir fuerzas que actúan sobre o dentro de un individuo para iniciar y dirigir la conducta de este, también se puede usar este término para explicar y entender las diferencias en la intensidad de la conducta, siendo más intensas como resultado de los más elevados niveles de motivación (Palmero, 2008). Entender la motivación como un elemento clave de la experiencia, significa pensarla, como propone Dann (1981), como un estado mental que predispone a un actor o un grupo de actores a viajar.

Las representaciones que motivan el viaje no son las mismas que compartirán al regreso a sus hogares, reflexiona Bertoncello (2006), entra en juego entonces otro factor fundamental en la construcción de la experiencia, la satisfacción. En relación a ella Palmero argumenta que

si se quiere delimitar con mayor precisión el pro-
ceso de motivación hay que analizar (...) qué
ocurre desde que un estímulo es detectado (...),
hasta qué se consigue, bien el objetivo y/o la sa-
tisfacción de la necesidad, bien el eventual fraca-
so. $(2008$, p. 12$)$

Se la puede considerar como un juicio de naturaleza cognitiva o de carácter afectivo que deriva de las experiencias del individuo, proponen Fernández, García y Picos (2010). Sin embargo, 
también comprende las facultades del intelecto y la voluntad, asegura Dann (1981).

En este contexto en donde se posiciona la subjetividad como elemento clave para entender el significado de los destinos turísticos, la percepción se plantea como otro componente central. Por lo tanto, la misma es un concepto más complejo que un simple mecanismo para ver el mundo que nos rodea (Nogué i Font, 1992). Es la forma en que los sujetos sociales aprehenden los acontecimientos de la vida diaria, ella depende de dos factores fundamentales: el aprendizaje y experiencia generada a lo largo de la vida y la percepción y el conocimiento heredado. Estos elementos no son iguales de un individuo a otro, por lo cual, la percepción en relación a un determinado acontecimiento va a ser particular, ya que los individuos perciben el mundo exterior según el mundo interior propio. La percepción está, entonces, atravesada por un marco referencial propio e individual, resultado de la experiencia y de la cultura, así como también de las expectativas, aspiraciones y valoraciones que estos generan (Daverio, Mosti, Malmierca, Arcos y Arias, 2007).

En consecuencia, la experiencia se plantea como una de las múltiples razones que lleva a que los individuos opten por un destino, evidenciando los aspectos que más valor adquieren y que deben ser trabajados y reforzados para que el destino no solo continúe en el mercado, sino que, además, se fortalezca. Este tema adquiere, incluso, una mayor complejidad cuando al turismo de cruceros se refiere, dado que se trata del resultado de la estrecha relación que se genera entre el buque y los puertos de destino, "para las líneas de crucero es muy importante que la experiencia del pasajero sea tan buena como para que no perciba diferencia entro los servicios que tienen a bordo con los servicios en tierra" (Brida et al., 2010, p. 4). Como expresa Henthorne (2000 en Andriotis y George, 2010), seleccionan puertos particulares, esperando brindar a sus clientes experiencias positivas, y están dispuestas a cambiar los itinerarios y/o eliminar puertos si un número excesivo de clientes no quedan conformes con la experiencia vivida.

El sentido de "matriz decisional externa" que es reiteradamente propuesto por Boisier (1997; 1998; 2005)tarea nada de fácil, como es posible entrever. Será necesario, en primer lugar, dejar en claro qué se entenderá por "globalización" en este contexto; en se- gundo lugar, habrá que develar las relaciones entre el proceso de globalización y el territorio, asunto para algunos ambiguo o resuelto fal- samente por la "muerte" del territorio y de la geografía; en tercer lugar, será necesario establecer si algo como el "desarrollo local" pertenece a la lógica globalizadora, aclarando de paso las diversas interpretaciones del concepto $y$, por último, se tendrá que examinar las contribuciones - si las hubiera- de las universidades y del mismo desarrollo local a la globalización, al funcionamiento de bloques supranacionales (como el Mercosur, por ejemplo se ve claramente expresado en el turismo de cruceros. Con movimientos de flujos turísticos caracterizados por encontrarse exógenamente determinados, es desde el propio territorio que se puede influir optimizando los recursos endógenos y el conocimiento de su funcionamiento, plantean Jensen y Vereda (2016). En este sentido, como expresa Troncoso (2008) un lugar turístico es más que el simple ámbito de interacción entre turistas y población local, implica un proceso de valoración del espacio a partir de una práctica social específica que dará lugar a una serie de actividades económicas. La concreción de la visita exige de un conjunto de servicios y su producción eficiente y eficaz pueden impactar positivamente en la construcción y reconstrucción de interdependencias de los lugares (Silveira, 2011), ello requiere, sin embargo, conocer sobre qué aspectos se debe centrar la atención para aprovechar este posicionamiento, potenciar las capacidades propias del territorio y trabajar en aquellos que sean susceptibles de formar parte de la experiencia.

Como expresa Boisier (1997)tarea nada de fácil, como es posible entrever. Será necesario, en primer lugar, dejar en claro qué se entende- 
rá por "globalización" en este contexto; en segundo lugar, habrá que develar las relaciones entre el proceso de globalización y el territorio, asunto para algunos ambiguo o resuelto fal- samente por la "muerte" del territorio y de la geografía; en tercer lugar, será necesario establecer si algo como el "desarrollo local" pertenece a la lógica globalizadora, aclarando de paso las diversas interpretaciones del concepto $y$, por último, se tendrá que examinar las contribuciones - si las hubiera-de las universidades y del mismo desarrollo local a la globalización, al funcionamiento de bloques supranacionales (como el Mercosur, por ejemplo está en el territorio la decisión de cómo operar esa matriz y poner en valor las repercusiones que el crucerismo genera. Para ello es fundamental pensar al mismo como un segmento completo y complejo que está dirigido a un público con intereses y perfiles diversos (Brida et al., 2010).

\section{CONSIDERACIONES METODOLÓGICAS}

En esta investigación se aplicó la técnica de la encuesta considerada un instrumento que permite acceder de forma directa y simple a las opiniones, actitudes y valoraciones de las personas respecto de un fenómeno. El cuestionario se aplicó a los cruceristas que visitaron la ciudad de Ushuaia a bordo de cruceros que realizan itinerarios pendulares, recorriendo la costa del Atlántico Sur y Pacífico Sur desde Montevideo/ Buenos Aires hasta Valparaíso y viceversa.

Se tomó como universo de análisis el total de cruceristas que responden a este segmento y que arribaron a la ciudad durante la temporada 2014/2015. En base a los datos brindados por el InFueTur (2015), 90.276 turistas visitaron a Ushuaia en ese período, de ellos 36.625 corresponden al grupo de buques antárticos (Vereda y Jensen, 2015) que no fueron considerados para esta investigación. Esta decisión no fue azarosa, sino que responde a dos cuestiones. Por un lado, el perfil de turista antártico; las investigaciones que se vienen realizando sobre él lo describen como un grupo cuya principal, y en ocasiones única motivación, es conocer la Antártida en cuyo caso, los puertos de recalada son considerados como un destino 'de paso' para llegar a cumplir con el objetivo final. Por el otro, posicionar a los cruceros de gran porte como tema de investigación. Hay un interesante y fuerte desarrollo de investigaciones que abordan a los buques antárticos, situación que no se refleja en el caso de los grandes cruceros.

En este marco, el tamaño del universo se redujo a 53.651 pasajeros. El trabajo de campo se llevó a cabo durante las temporadas de verano 2015/2016, 2016/2017 y 2017/2018, entre los meses de octubre a abril, período en el cual arriban los cruceros, logrando reunir un total de 435. Las mismas fueron distribuidas a los cruceristas al finalizar las excursiones que ofrecen las agencias de viajes locales horas antes de embarcar para continuar con su recorrido por la Patagonia. Esta selección responde a la necesidad de que el visitante pueda conocer y recorrer la ciudad y sus alrededores para luego responder las preguntas referidas a Ushuaia.

El cuestionario (Anexo 1) consistió en preguntas de tres tipos: cerradas, que se dividieron en dicotómicas, de opción binominal (sí o no), y de respuesta múltiple donde debían optar por la o las respuestas que creían más convenientes. Las preguntas abiertas se aplicaron cuando el fin era conocer la opinión del encuestado respecto de un punto específico del tema y, por último, las preguntas de escala se utilizaron para conocer el grado de relevancia, acuerdo e interés de los encuestados sobre determinados aspectos del fenómeno en análisis. Para ellas, se utilizó la técnica de Likert generando afirmaciones con cinco niveles posibles de respuestas, donde 1 representaba el menor grado de interés y 5 el mayor, para que las pudieran evaluar en función de su criterio subjetivo. Para la conformación de la encuesta se consideraron variables para conocer la opinión de Ushuaia como puerto de cruceros. Para tal fin se consideraron las siguientes definiciones operativas: 
-Perfil del visitante: Derivado del nivel socioeconómico, se pretende conocer las características de los cruceristas.

-Motivaciones: Consiste en contar con información que permita analizar los principales factores que incidieron al momento de optar por este tipo de viaje y destino.

-Valoración de los atractivos y actividades turísticas: Permite conocer el grado de importancia sobre la conformación de la oferta turística del destino Ushuaia.

-Valoración de los servicios turísticos: Recaba información sobre el grado de importancia que conforma para la oferta turística la presencia o ausencia de determinados servicios turísticos.

-Grado de satisfacción alcanzado: Permite conocer la opinión de los cruceristas en relación a su experiencia y si la misma permitió cumplir con las expectativas generadas sobre el viaje.

Una vez recolectada la información se procedió al uso del software estadístico SPSS (versión 20) para analizar las variables relacionadas con el enfoque cuantitativo. El procesamiento de los datos e interpretación de los mismos permitió conocer con mayor profundidad las características que revisten al tema de estudio y desarrollar los objetivos que tenían como eje estructurante el uso de encuestas y la medición de sus resultados. Se generaron gráficos, tablas y figuras para representar la información de forma clara y precisa y fue acompañada por una reflexión e interpretación de la misma complementada con bibliografía específica del tema.

\section{RESULTADOS}

En principio, se exponen algunos elementos que sintetizan cómo se desarrolla la actividad de cruceros en Ushuaia, contribuyendo a contextualizar la evidencia empírica que se presenta posteriormente como resultados de la investigación. En la Tabla 1 se observa el comportamiento de los cruceros en Ushuaia para la temporada 2016/2017, para este análisis se consideraron los cruceros definidos como 'Pendulares o al Cono Sur'.

Al centrar la atención en los cruceros que conforman este grupo (Pendulares), una vez que arriban al puerto de Ushuaia, permanecen entre siete y doce horas recorriendo la ciudad o realizando excursiones. Los buques ofrecen distintos tipos de excursiones que se detallan en la Tabla 2, los pasajeros contratan estos servicios a bordo o bien realizan las actividades por su cuenta, dirigiéndose a las agencias de viaje locales. También hay grupos de pasajeros que optan por visitar los museos, caminar en la ciudad, realizar compras, comer en restaurantes, confiterías, entre otros.

La duración de las excursiones organizadas que se contratan a bordo depende de la permanencia del buque en el puerto. Para las navieras la venta de excursiones en tierra es un segmento especialmente importante desde el punto de vista económico, constituyendo $1 / 3$ de los ingresos extra (Butler 2008; Daverio, Jensen y Vereda., 2009).

Las excursiones más populares para los cruceristas son la 1 y 3 , dado que en poco tiempo alcanzan a conocer atractivos relevantes. Las excursiones 7, 8, 9, 10 y 11 son más específicas y solamente las contratan grupos pequeños. 
Tabla 1. Síntesis del comportamiento de cruceros en Ushuaia para la temporada turística estival 2017/2018*

\begin{tabular}{|c|c|c|c|c|}
\hline $\begin{array}{c}\text { Tipo de } \\
\text { crucero s/ } \\
\text { área de visita }\end{array}$ & $\begin{array}{l}\text { Itinerario modelo } \\
\text { de navegación }\end{array}$ & $\begin{array}{c}\text { Puerto/s de recam- } \\
\text { bio de pasajeros }\end{array}$ & $\begin{array}{l}\text { Cantidad de bu- } \\
\text { ques y compañías }\end{array}$ & Viajes \\
\hline $\begin{array}{l}\text { Canales } \\
\text { Fueguinos }\end{array}$ & $\begin{array}{l}\text { Punta Arenas/Estre- } \\
\text { cho de Magallanes/ } \\
\text { Canal Beagle/Cabo } \\
\text { de Hornos/Ushuaia. } \\
\text { Cinco días de } \\
\text { navegación. }\end{array}$ & $\begin{array}{l}\text { Punta Arenas y, } \\
\text { en menor medi- } \\
\text { da, Ushuaia. }\end{array}$ & $\begin{array}{l}\text { dos buques que } \\
\text { pertenecen a la } \\
\text { misma compa- } \\
\text { ñía domicilia- } \\
\text { da en Chile. }\end{array}$ & $\begin{array}{l}30 \text { y } 11 \text { viajes cada } \\
\text { buque que, a su } \\
\text { vez, transporta- } \\
\text { ron un promedio } \\
\text { de } 170 \text { pasajeros } \\
\text { en cada viaje. }\end{array}$ \\
\hline
\end{tabular}

$\begin{array}{ll} & \text { Ushuaia/Península } \\ & \text { Antártica/Ushuaia. } \\ & \text { En algunos casos } \\ & \text { se incluyen las } \\ \text { Viajes } & \text { Islas Malvinas y } \\ \text { Antárticos } & \text { Georgias del Sur. } \\ & \text { Nueve días de } \\ & \text { navegación, los } \\ & \text { más extensos llegan } \\ & \text { hasta veinte días. }\end{array}$

Ushuaia es la puerta de entrada más activa de la modalidad marítima, concentra más del 90\% de los flujos totales.
33 buques de compañías diversas, todas domiciliadas en el extranjero, a excepción de una radicada en Ushuaia.
256 viajes. La mayoría de los viajes (98\%) transportó menos de 500 pasajeros por viaje) y solamente el $2 \%$ más de 500 , entre $740 y$ 2100 pasajeros.

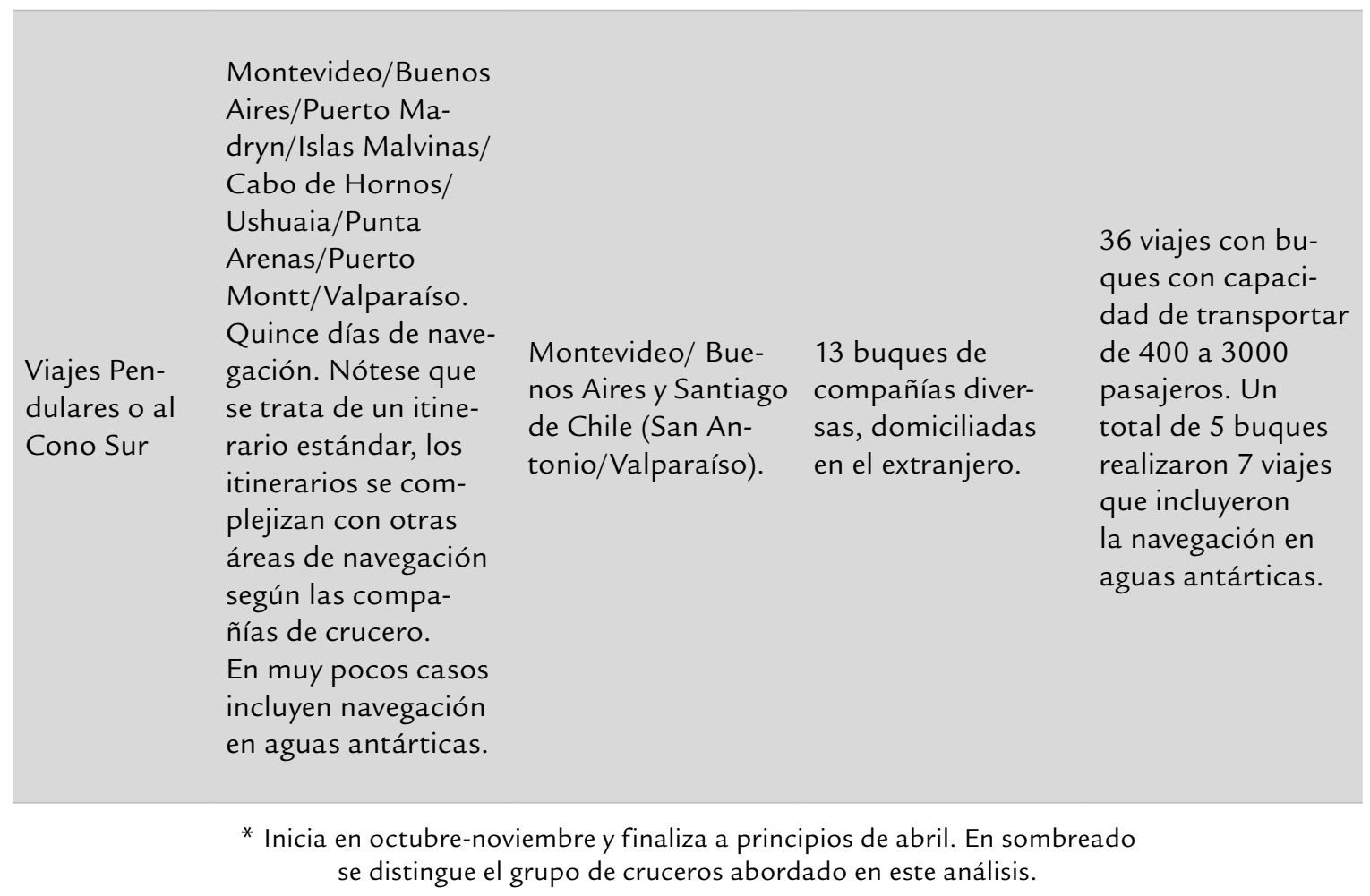

Fuente: elaboración personal con base en información suministrada por el proyecto de investigación PIDUNTDF A 6/2016 
Tabla 2. Excursiones ofrecidas para visitar la ciudad

\begin{tabular}{|c|c|c|c|}
\hline & Excursión & $\begin{array}{l}\text { Dura- } \\
\text { ción }\end{array}$ & Características \\
\hline 1 & $\begin{array}{l}\text { Navegación } \\
\text { Canal Beagle }\end{array}$ & $2: 30$ hs. & $\begin{array}{l}\text { Recorrido en barco (catamarán), se visitan islas con fauna } \\
\text { silvestre, lobos marinos de uno y de dos pelos y aves tales } \\
\text { como cormoranes imperiales, roqueros, gaviotines suda- } \\
\text { mericanos, quetros, entre otros. Además, el faro Les Eclai- } \\
\text { reurs en el archipiélago homónimo, resulta otro atractivo. }\end{array}$ \\
\hline 2 & $\begin{array}{l}\text { Navegación Canal } \\
\text { Beagle y Estan- } \\
\text { cia Harberton }\end{array}$ & 6 hs. & $\begin{array}{l}\text { Ídem anterior, se suman más horas de navega- } \\
\text { ción y se visita el sitio histórico Estancia Har- } \\
\text { berton y la pingüinera de Isla Martillo. }\end{array}$ \\
\hline 3 & $\begin{array}{l}\text { Parque Nacional } \\
\text { Tierra del Fuego } \\
\text { (PNTDF) con tren }\end{array}$ & $3: 30$ hs. & $\begin{array}{l}\text { Visita al área protegida donde se destacan atrac- } \\
\text { tivos relacionados con la naturaleza, se recorre un } \\
\text { área muy pequeña del PNTDF y se combina la vi- } \\
\text { sita con un paseo en el tren que recrea el trans- } \\
\text { porte de los presos para trabajar en el bosque. }\end{array}$ \\
\hline 4 & $\begin{array}{l}\text { Parque Nacional } \\
\text { Tierra del Fuego }\end{array}$ & 4 hs. & $\begin{array}{l}\text { Se visita el área protegida en ómnibus, donde se } \\
\text { destacan atractivos relacionados con la naturale- } \\
\text { za y se llega al final de la ruta nacional } N^{\circ} 3 \text {. }\end{array}$ \\
\hline 5 & $\begin{array}{l}\text { Visita a la ciudad } \\
\text { con museos } y / 0 \\
\text { galería temática }\end{array}$ & $2 / 3$ hs. & $\begin{array}{l}\text { Dependiendo de los museos que se visiten (Fin del } \\
\text { Mundo y/o del Presidio y/o galería temática), es } \\
\text { una visita por la ciudad, de contenido cultural. }\end{array}$ \\
\hline 6 & Lago Escondido & 6 hs. & $\begin{array}{l}\text { Recorrido en ómnibus hacia el norte y este de Us- } \\
\text { huaia, se cruza la cordillera de los Andes por el paso } \\
\text { Garibaldi, visita contemplativa de naturaleza. }\end{array}$ \\
\hline 7 & $\begin{array}{l}\text { Excursión } 4 \times 4 \\
\text { / offroad }\end{array}$ & 4 hs. & $\begin{array}{l}\text { Excursión de aventura en áreas bosco- } \\
\text { sas en un vehículo doble tracción. }\end{array}$ \\
\hline 8 & $\begin{array}{l}\text { Excursión de } \\
\text { pesca deportiva }\end{array}$ & 6 hs. & $\begin{array}{l}\text { Excursión para realizar pesca con mosca } \\
\text { de salmónidos con devolución }\end{array}$ \\
\hline 9 & Excursión culinaria & 3 hs. & $\begin{array}{l}\text { Visita a distintos establecimientos relaciona- } \\
\text { dos con la gastronomía local (ahumadero, res- } \\
\text { taurant, casa de vinos, entre otros). }\end{array}$ \\
\hline 10 & Observación de aves & 5 hs. & $\begin{array}{l}\text { Excursión que se desarrolla en el Parque Nacional Tierra } \\
\text { del Fuego, liderados por un guía especializado en avifauna. }\end{array}$ \\
\hline 11 & Excursión en canoa & 5 hs. & $\begin{array}{l}\text { Excursión que se desarrolla en el Parque Nacional Tie- } \\
\text { rra del Fuego, navegando por el lago Acigami, ríos } \\
\text { Lapataia y Ovando hasta llegar al Canal Beagle. }\end{array}$ \\
\hline
\end{tabular}

Fuente: elaboración personal con base en las excursiones ofrecidas por las principales navieras que visitan Ushuaia

PERFIL SOCIO-DEMOGRÁFICO DE LOS CRUCERISTAS

Los resultados del perfil socio-demográfico (Tabla 3) hacen mención a los rasgos que caracterizan a estos visitantes de cruceros pendula- res. En primer lugar, se destaca su rango etario que remarca una modalidad de turismo tradicionalmente asociada a los mayores de 60 años. El grupo que se ubica en segundo lugar corresponde a los visitantes de entre 45-64 años, con 
una diferencia considerable en su porcentaje de participación, pero que permite reflejar una leve coincidencia con los cambios que actualmente se observan en el turismo de cruceros a nivel mundial. En relación con el nivel de ocupación, es la opción 'jubilados' la que lidera los resultados, seguido por 'empleado'. En cuanto al ingreso, a pesar de la masificación que está atravesando este segmento para el caso de los cruceristas pendulares del cono sur de América, continúan dominando el mercado los grupos que poseen un alto nivel adquisitivo.

Al considerar el nivel de educación y con quienes visitan el destino, coincide con la tendencia global del crucerista planteada por Tamayo Tamayo (2003), quien destaca que el mayor porcentaje asegura tener estudios de nivel terciario/ universitario o de posgrado, así como realizar el viaje en pareja principalmente. Lo mismo sucede sobre la opción 'residencia' donde la información relevada a lo largo de la investigación refleja que el $65,3 \%$ de los cruceristas, provienen de América, seguido por Europa.

Al profundizar al interior de cada continente se observa un comportamiento que se condice con la tendencia mundial expresada por Rodrigue y Notteboom (2013). América del Norte concentra el mayor porcentaje de cruceristas, siendo Estados Unidos el que agrupa el 40,9\% de los pasajeros. Se mantienen entonces como los principales consumidores de este segmento, seguidos por Canadá con el 13,11\%. Europa por su parte está liderado por Reino Unido con un $12 \%$, mientras que la participación de Oceanía se concentra en Australia, pero en menor medida, representando solo el $6 \%$.

Tabla 3. Perfil socio-demográfico de los cruceristas

\begin{tabular}{|c|c|c|c|c|c|c|c|}
\hline Variable & & Variable & $\%$ & Variable & $\%$ & Variable & \\
\hline \multicolumn{2}{|c|}{ Género } & \multicolumn{2}{|c|}{ Edad } & \multicolumn{2}{|c|}{ Residencia } & \multicolumn{2}{|c|}{$\begin{array}{c}\text { Ingreso } \\
\text { (total mensual en U\$S) }\end{array}$} \\
\hline Masculino & 37,9 & $18-24$ & 1,4 & América & 65,3 & $0-1700$ & 1,4 \\
\hline Femenino & 56,6 & $25-44$ & 9 & Europa & 22,3 & $1701-3456$ & 23 \\
\hline \multirow[t]{3}{*}{$\mathrm{NsNc}$} & 5,5 & $45-64$ & 31 & Oceanía & 5,5 & 3457 ó más & 40,2 \\
\hline & & 65 ó más & 51,7 & Otros & 0,7 & $\mathrm{NsNc}$ & 35,4 \\
\hline & & $\mathrm{NsNc}$ & 6,9 & $\mathrm{NsNc}$ & 6,2 & & \\
\hline
\end{tabular}

\begin{tabular}{|c|c|c|c|c|c|c|c|}
\hline Variable & $\%$ & Variable & $\%$ & Variable & $\%$ & Variable & $\%$ \\
\hline \multicolumn{2}{|c|}{ Estado Civil } & \multicolumn{2}{|c|}{ Ocupación } & \multicolumn{2}{|c|}{ Estudios } & \multicolumn{2}{|c|}{ Visita destino } \\
\hline Soltero & 14 & Empleado & 22,3 & Sin estudios & 2,3 & Solo & 7,1 \\
\hline Casado & 69,7 & Desempleado & 1,4 & Primario & 0,9 & En pareja & 65,9 \\
\hline Separado & 1,1 & Independiente & 11,7 & Secundario & 8,8 & En familia & 13,6 \\
\hline Divorciado & 4,8 & Jubilado & 57,9 & Terc./Univ. & 44,8 & Con amigos & 7,6 \\
\hline En pareja & 4,4 & Ama/o de casa & 1,8 & Posgrado & 35,6 & Otros & 2,1 \\
\hline Viudo & 3,2 & Estudiante & 2,5 & $\mathrm{NsNc}$ & 7,6 & $\mathrm{NsNc}$ & 3,7 \\
\hline $\mathrm{NsNc}$ & 2,8 & $\mathrm{NsNc}$ & 2,3 & & & & \\
\hline
\end{tabular}

Fuente: elaboración personal con base en las temporadas de análisis 2015/2016, 2016/2017 y 2017/2018 


\section{MOTIVACIONES PARA TOMAR UN CRUCERO POR LA REGIÓN}

Uno de los componentes de la experiencia es la motivación. Actúa para iniciar y dirigir una conducta y permite analizar la etapa a priori del viaje, es decir, saber qué hizo que los cruceristas optaran por tomar el crucero. Para su indagación se les solicitó a los cruceristas que indicaran las diferentes motivaciones que intervinieron en su decisión de realizar el viaje y en qué nivel de relevancia influyeron, siendo 1 la motivación menos relevante y 3 la motivación más relevante. Se obtuvieron un total de 1.611 respuestas.

Las decisiones con más peso al momento de elegir tomar este crucero corresponden a 'conocer el Sur de Sudamérica' y 'conocer la Patagonia' (Figura 4). Este dato es significativo cuando se piensa que la práctica turística implica un desplazamiento espacial, siendo los lugares turísticos elegidos por la expectativa de lo diferente (Almirón, 2004; Vereda, 2016). En este sentido, dos características pueden pensarse como fundamentales para que estas opciones sean consideradas, por un lado, el rol que juega la posición geográfica como activador de la motivación, donde la distancia se carga de valor positivo $y$, por el otro, relacionado con lo anterior, la dimensión subjetiva que motiva la práctica turística.

En palabras de Bertoncello (2006) la Patagonia adquiere el significado de lugar distante y ajeno a todo lo demás, representación que remite a varias dimensiones y consolida la fuerte de atractividad turística de la región. Estas opciones reflejan el peso que tiene el espacio como una dimensión constitutiva fundamental para el desarrollo de la actividad turística a partir de sus formas de apropiación materiales y/o simbólicas.

Otra de las opciones más elegidas fue 'por el paisaje'. El itinerario que ofrecen las empre- sas de cruceros en este recorrido condice con una mirada del espacio como escenario de procesos sociales en donde se refleja una gran diversidad y variedad de paisajes. Ejemplo de ello son las ciudades puerto de Buenos Aires, descripta por Bertoncello y Troncoso (2014) como una ciudad moderna y cosmopolita, puerta de entrada del turismo internacional; y la prístina Ushuaia con sus excursiones por la naturaleza patagónica cuyas características muestran atributos únicos en términos de belleza natural (Bertoncello, 2006).

La motivación 'navegar en crucero' tiene también un peso importante. Esta respuesta es consistente con una de las principales características del turismo de cruceros, que consiste en proponer al viaje en sí mismo como parte del destino (Wood, 2004). En esta decisión es el crucero el que actúa como determinante, pero depende de cada puerto tener la capacidad de consolidarse como un espacio vinculante e interactivo a esta actividad. A partir de ello, otra de las motivaciones seleccionada que adquiere importancia son 'los atractivos que poseen los puertos de visita' lo cual refleja el interés que despierta cada puerto al momento de decidir tomar el crucero.

En esta última afirmación resulta de particular interés pensar qué lugar ocupa Ushuaia en el itinerario. Planteada como un espacio de paisajes deslumbrantes (Norwegian Cruise Line $)^{4}$, las montañas caracterizadas por sus alturas y sus pendientes pronunciadas, la combinación de roca y vegetación, así como la presencia de cuerpos de aguas cristalinos representan un paisaje idealizado. Esto podría reflejar la construcción de una identidad turística de la ciudad más relacionada con los aspectos naturales del destino.

4 https://www.ncl.com/ar/es/Puertos-de-cruceros/Buenos-Aires-Argentina-qhft/ 
Figura 4. Motivaciones para realizar el viaje en crucero

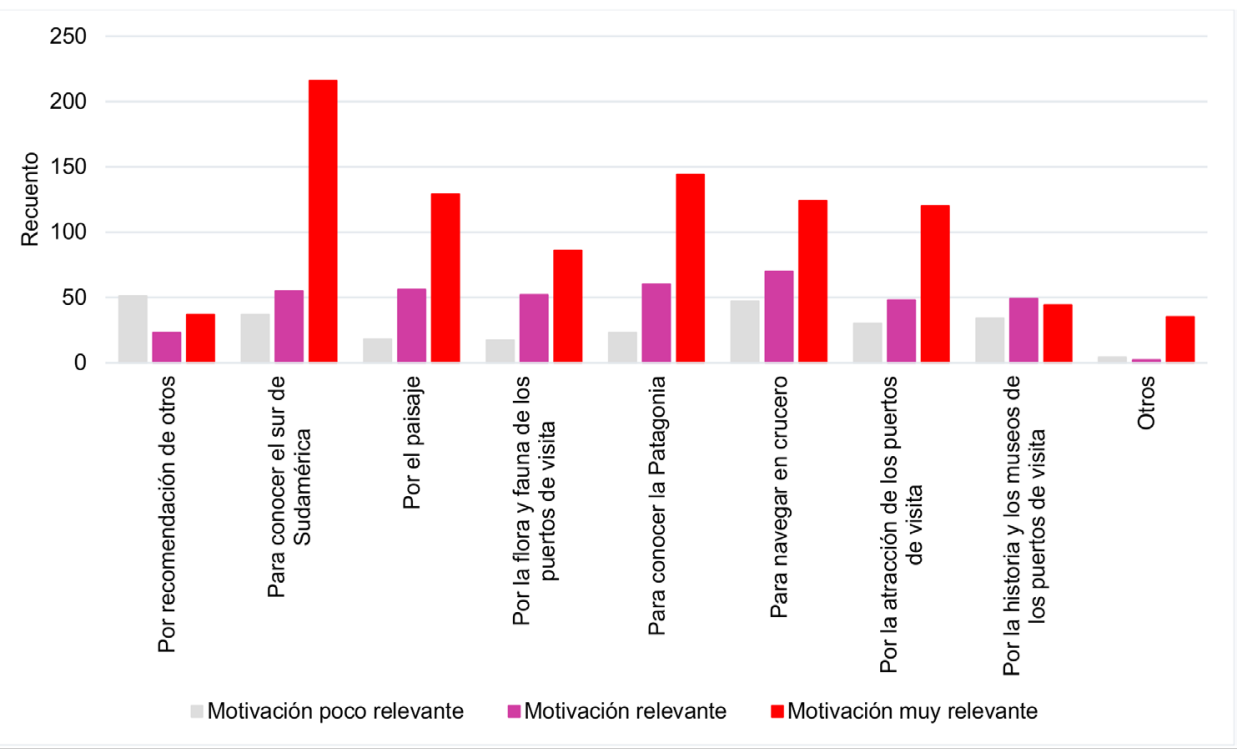

Fuente: elaboración personal con base en las temporadas de análisis 2015/2016, 2016/2017 y 2017/2018

Hacia el interior de las motivaciones es interesante analizar el comportamiento a nivel general $y$ algunas de las afirmaciones con mayor detalle. Desde una mirada global, se destaca que aquellas opciones que fueron más veces elegidas, coinciden con una alta valoración en relación a su relevancia y, en consecuencia, su elección disminuye a medida que se reduce la relevancia de dichas motivaciones. Esta característica es observable en todas las opciones con excepción de dos; la que corresponde a la motivación 'por la historia y los museos de los puertos de visita' y 'por recomendación de otros'.

En el primer caso, se observa que las actividades relacionadas con la historia y los museos se manifiestan como una motivación relevante. Se reconoce que en el recorrido por Sudamérica los cruceros recalan en ciudades que se caracterizan por presentar una rica y diversa oferta relacionada con la historia y la cultura, como Montevideo, Buenos Aires y Valparaíso. Sin embargo, las diferentes atracciones ofrecidas, en este sentido, no son lo suficientemente valoradas como para adquirir la denominación de motivación muy relevante.

Situación similar ocurre con la opción 'por recomendación de otros' la cual se destaca por presentar más respuestas asociadas a una moti- vación poco relevante, siendo el único caso que muestra este comportamiento. El mismo podría relacionarse con el lugar que ocupa actualmente el turismo de cruceros en Sudamérica. Como se mencionó previamente, si bien ha demostrado un aumento constante y considerado, sigue siendo aún un segmento en crecimiento, lo que permite pensar que el porcentaje de cruceristas que han realizado este itinerario todavía no actúa como comunicador significativo de esta experiencia.

Por último, se destaca la opción 'otros'. Esta fue la menos seleccionada, pero resulta de interés destacar que su peso se concentra en el ítem de motivación muy relevante. Al interior de esta opción se destaca que muchos encuestados la eligieron por la posibilidad de complementar el viaje con otra actividad, como la posibilidad de visitar familiares o amigos en los puertos de visita. En otros casos destacaron que a través del turismo de cruceros tienen la oportunidad de conocer y recorrer una gran variedad y diversidad de destinos en un mismo viaje e incluso hicieron mención a la posibilidad de conocer la Antártida.

\section{PERCEPCIÓN DE UshUAIA COMO DESTINO DE CRUCEROS}

A través de la percepción es posible analizar la forma en que los turistas aprehenden los 
acontecimientos de su viaje, planteándose la misma como un concepto bastante más complejo que ser pensado solo como la forma en la que se capta el mundo (Nogué i Font, 1992). Plantear el análisis desde la percepción permite comprender al turismo desde la impronta social y tener una mirada al interior de cada destino. Las preguntas realizadas en relación a la percepción plantearon, por un lado, conocer la opinión sobre el destino a través de una escala de Likert de cinco categorías donde 1 corresponde a la menor valoración y 5 a la mayor valoración. Por el otro, observar cómo caracterizan la ciudad, mediante una pregunta abierta en la cual los cruceristas utilizaron tres palabras para identificar a Ushuaia, las mismas luego fueron agrupadas bajo un conjunto de palabras. A partir de allí se llevó a cabo el análisis de las variables propuestas.

En relación con la percepción que los cruceristas tienen sobre Ushuaia, se observa un comportamiento, en general homogéneo, donde es mayor el número de respuestas que afirman estar muy de acuerdo con las opiniones mencionadas. A esta tendencia escapan dos afirmaciones: la relevancia de los atractivos culturales y la diversidad de atractivos que posee la localidad, que reflejaron el menor número de respuestas asociadas a 'totalmente de acuerdo' (Figura 5).
La opción 'belleza paisajística' se distingue no solo por haber sido la más elegida sino, además, por la alta valoración que obtuvo. El paisaje, se plantea entonces como una de las imágenes que se tiene como parte del esquema mental que se construye en referencia a este destino. Resulta significativa la valoración que adquiere esta afirmación si consideramos al paisaje como un concepto complejo y completo, el mismo puede ser pensado no solo desde sus aspectos físicos sino, como expresa Santos Solla (2008), desde una mirada integral, como expresión del territorio, de su economía y sociedad y de la construcción de su cotidianidad. Esto conlleva, además, a pensar la percepción del destino no solo desde los aspectos materiales sino también desde sus cualidades intangibles.

En este sentido, se destaca la valoración que obtuvieron las opciones 'agradable', 'seguro para viajar' y 'relajante'. Es actualmente reconocido que el turista busca, en la realización de su viaje, encontrarse algo diferente o extraordinario. Gran parte de los visitantes que arriban a Ushuaia provienen de grandes ciudades, donde la urbanización ha absorbido buena parte de la dinámica social y en la recurrente oposición a los contextos urbanos, altamente poblados y artificializados (Bertoncello, 2006), Ushuaia se percibe como un destino calmo y placentero.

Figura 5. Opinión acerca de Ushuaia como destino de cruceros

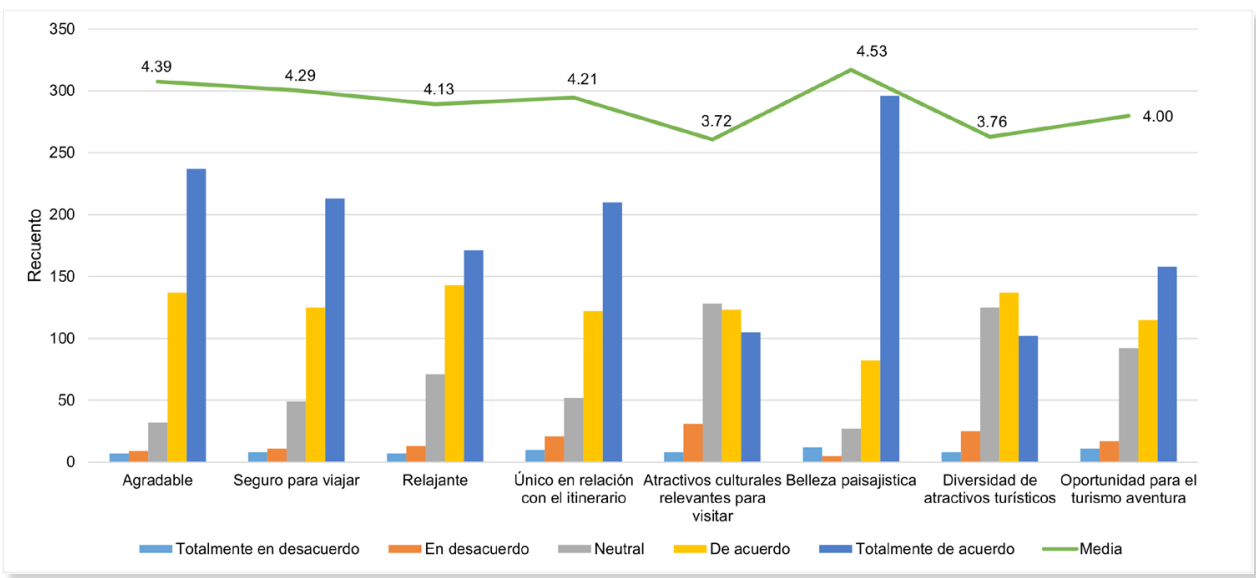

Fuente: elaboración personal con base en las temporadas de análisis 2015/2016, 2016/2017 y 2017/2018 
La opción 'único en relación con el itinerario' obtuvo también una valoración significativa. La singularidad $y / 0$ unicidad son factores que pueden favorecer positivamente al destino, ya que esto implica que solo en él tendrán la posibilidad de conocer y disfrutar esa característica que lo reviste como tal. Sin embargo, al tomar en consideración la opinión que se tiene en relación con la relevancia de los atractivos culturales, como así también de la diversidad de atractivos que posee el destino, es posible considerar que estas dos características suman a la valoración de Ushuaia como destino, pero no llegan a definirla como tal. En contraposición a esta observación se destaca la participación del turismo de aventura, o bien de las características paisajísticas e intangibles de la localidad, lo que permitiría pensar que la percepción que se tiene sobre Ushuaia como destino de cruceros se asocia más a sus factores naturales y simbólicos.

Más allá de las diferencias que pueden observarse al interior de las opciones, se aprecia una alta valoración general. Todos los casos superaron la media y la belleza paisajística fue la que obtuvo la mayor valoración. Esta percepción que se genera en torno a Ushuaia es posible complementarla con las palabras utilizadas por los cruceristas para identificar a la ciudad (Figura 6). El paisaje, como símbolo y significado de los lugares que tiene la capacidad de expresar pensamientos, ideas y emociones (Nogué y Vela, 2011) es un concepto al que recurren los cruceristas en el contexto de su experiencia. El valor otorgado a esta característica se observa también en la identificación de Ushuaia como destino de cruceros donde el paisaje es mencionado en un $21 \%$.

No es solo el concepto de paisaje lo que despierta atención en los visitantes de cruceros, sino el significado que los mismos le dan. Es así que el valor otorgado a la belleza paisajística se puede complementar con el rol que cumple la naturaleza en el imaginario de los cruceristas, siendo mencionada en un $38 \%$. La conjunción de ambas afirmaciones permite analizar al destino desde el concepto de paisaje natural el cual presupone la existencia de unos paisajes en los que la acción del hombre es nula o insignificante (Nogué i Font, 1992). En la construcción de la imagen de Ushuaia los elementos y atributos naturales cumplen un rol fundamental como integrantes de su identidad territorial.

La representación simbólica también interviene en la definición de este espacio turístico. Como plantean Lash y Urry (1998) los visitantes se ven atraídos por los mitos del lugar que envuelven al destino y a partir del cual se construye su imagen. La elección de ser único en el itinerario se plantea como rasgo esencial de la identificación de Ushuaia. La unicidad expresada por los visitantes puede relacionarse con el concepto de 'fin del mundo' que es propuesto por los cruceristas como una de las palabras que identifican al destino. Esta característica que fue mencionada en un $23 \%$, adquiere un peso importante en el imaginario de los cruceristas y es un componente fundamental del sentido de lugar de este espacio turístico.

Al hablar del 'fin del mundo' no se hace referencia únicamente a la lejanía geográfica medida en kilómetros, sino que, además, responde al imaginario creado en relación a esta palabra. Una distancia definida en términos de oposición y extrañamiento respecto de la vida y los lugares cotidianos de los turistas según expresa Bertoncello (2006). En otras palabras, materializa la visión que se tiene sobre los territorios periféricos, donde la distancia, como expresan Vereda y Jensen (2014), ocupa un lugar destacado en la configuración de lo lejano, entendiéndola en función de la concentración de las estructuras, poblaciones y actividades de la civilización moderna. Posición que es estratégicamente apropiada para la comercialización del destino.

Asociado a este concepto aparece la idea de extremo que es manifestada en un $8 \%$. Esta palabra no es considerada solamente desde la ubicación estratégica que posee el destino, sino que además busca expresar la esencia que reviste a Ushuaia desde su pristinidad y su componente natural como las mayores expresiones del territorio. Relacionado con esta palabra se encuentran expresiones como 'asombroso', 'de- 
solado' y 'solitario'.

En menor medida se utiliza la palabra 'amigable' para caracterizar al destino, que fue elegida en un $2 \%$, refiriéndose a la atención y conocimiento de los guías, así como al ca- rácter amistoso de los residentes. En el 8\% restante se agruparon las palabras que representaban otras características de Ushuaia, tales como 'historia y cultura', 'gastronomía' y 'tamaño de la ciudad'.

Figura 6. Principales características de Ushuaia desde la mirada de los cruceristas

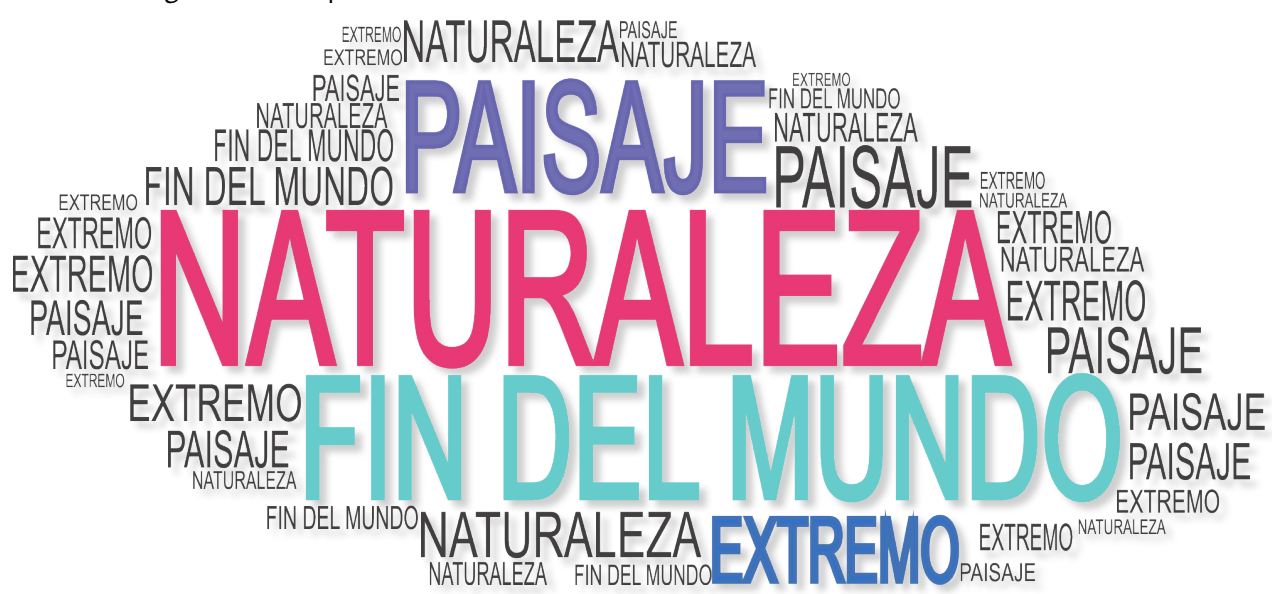

Fuente: elaboración personal con base en las temporadas de análisis 2015/2016, 2016/2017 y 2017/2018

\section{LA SATISFACCIÓN ADQUIRIDA}

La satisfacción es el otro factor que interviene en la experiencia de los visitantes. Este proceso planteado como una actitud que se adquiere una vez finalizado el viaje forma parte de la evaluación que hace el crucerista sobre su experiencia. Dos aspectos la conforman, por un lado, el emocional, relacionado con el sentimiento que generó la práctica turística y, por el otro, el cognitivo que responde a su evaluación en comparación con un estándar determinado (Campos Martínez y Yague Guillen, 2007). El primero implica respuestas a los objetivos propuestos para el viaje, mientras que el segundo se refiere a los productos físicos.

Como proceso que contribuye a completar la impresión que se tiene sobre el destino, este se abordó considerando diferentes aspectos. A través de una escala de Likert de cinco categorías, donde 1 corresponde a la menor valoración y 5 a la mayor valoración, se solicitó que expresaran el grado de satisfacción durante su visita y el grado de satisfacción sobre el gasto realizado en el destino, especificando en qué ítems se concentraron los mismos. Por otro lado, se indagó sobre su acuerdo o no con el tiempo de permanencia en la ciudad y su intención por repetir la visita, así como también por recomendar el destino.

En relación al grado de satisfacción expresado por los cruceristas los resultados demuestran que más de la mitad de los encuestados afirmó estar muy satisfecho con su visita en Ushuaia (Figura 7). La satisfacción es uno de los indicadores más utilizados para referirse a la calidad de la experiencia turística y recreativa, aseguran Daverio, et al. (2007). El resultado de esta afirmación juega, sin duda, un rol fundamental en la decisión que tomará el crucerista en relación con la experiencia de su visita. Al expresar una alta satisfacción se lee el sentimiento positivo que queda en el imaginario, lo que puede dar paso a un deseo de regresar al destino, e incluso a la construcción de lealtad sobre este puerto de visita, o bien, de recomendarlo. 
Figura 7. Grado de satisfacción de la visita a Ushuaia

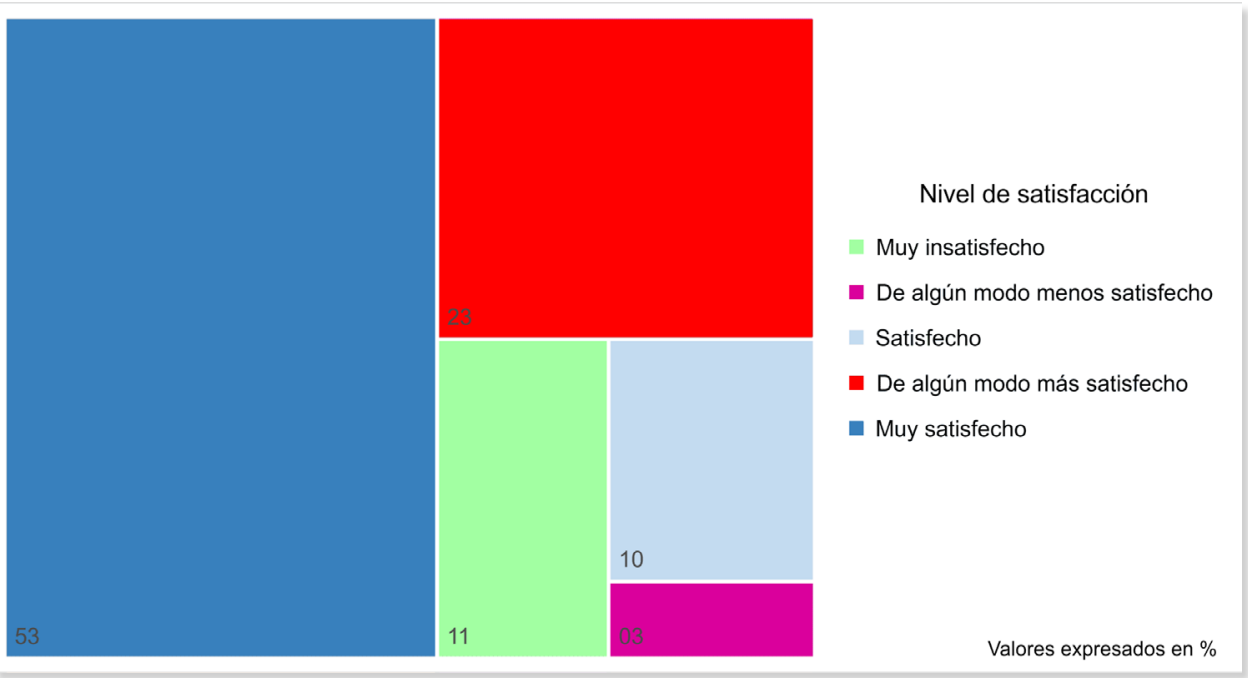

Fuente: elaboración personal con base en las temporadas de análisis 2015/2016, 2016/2017 y 2017/2018

El porcentaje que corresponde a muy insatisfecho, resulta también de interés para analizar. Si bien su valor no es alto, un $10 \%$ de los cruceristas no obtuvo los resultados esperados en la visita, y ello puede influir en la decisión que tome respecto del destino. Las justificaciones realizadas por los visitantes en relación a esta afirmación demuestran que en muchos casos la eligieron como consecuencia del poco tiempo que tuvieron para visitar la ciudad. Un importante número de los encuestados no profundizó sobre esa decisión y otro gran grupo denotó satisfacción en su opinión acerca de su visita a pesar de haber elegido la opción contraria. En estas respuestas, expresiones como la 'posibilidad de disfrutar la flora y fauna', 'conocer la historia de la localidad', 'ser atendidos cordialmente por los guías y agentes de turismo' o bien 'palpar la sensación de lo remoto y lo extremo' son las opiniones más mencionadas.

Si el turista no logra sentirse satisfecho con su visita, Oliveira (2011) plantea que además de disminuir la oportunidad de tenerlo nuevamente, su opinión puede influir en la toma de decisiones de potenciales turistas. Por ello, relacionado con la satisfacción se encuentra el interés por prolongar su estadía en Ushuaia (Figura 8). En este marco, el $75 \%$ de los encuestados respondió estar interesado en pasar más tiempo en el destino, expresando el $30 \%$ de ellos su deseo por quedarse dos días en la localidad.

Figura 8. Interés por permanecer más tiempo en Ushuaia

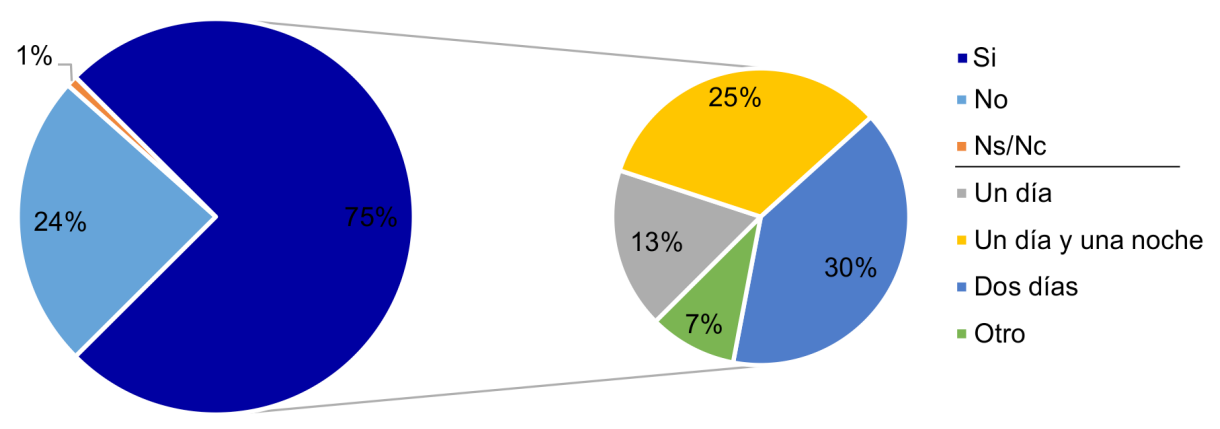

Fuente: elaboración personal con base en las temporadas de análisis 2015/2016, 2016/2017 y 2017/2018 
Esta manifestación no es menor si se tiene en cuenta que según el estudio realizado por Jensen y Daverio (2004) Ushuaia tiene la menor estadía promedio del itinerario variando, según la empresa ${ }^{5}$, entre 8 y 10 horas. Este resultado expresa una demanda por parte de los visitantes, que no responde al destino directamente, pero sí a la organización que se genera entre este y las empresas de cruceros. Muchos de los argumentos relacionados a la satisfacción de los cruceristas afirman que no han podido recorrer ni disfrutar de todos los atractivos que posee la localidad, por lo tanto, la mayor permanencia de los buques en el puerto de Ushuaia permitiría consolidar la actividad e incorporar nuevos espacios y productos.

De la mano de la satisfacción se encuentra el deseo de repetir la visita, que puede dar origen a la lealtad, la misma expresa la intención del turista por recurrir nuevamente al destino y esto depende en parte de la satisfacción que haya adquirido en su viaje. Se suele distinguir en dos

5 Se compararon las estadías de cuatro navieras que operan regularmente en la región (Royal Princess, Holland American Line, Celebrity Cruises y Norwegian Cruise Line). tipos: una comportamental vinculada a la repetición y otra actitudinal, relacionada como una actitud favorable hacia el destino. En palabras de Fernández et al. (2010) la primera, plantea la seguridad de que se ha producido la repetición de la visita, al menos una vez $y$, la segunda, incorpora el elemento intencional o de previsible comportamiento futuro, por ello la denomina lealtad futura, intencional o actitudinal.

A partir de la pregunta realizada en relación con la intención de volver a visitar el destino, se observa un alto grado de lealtad actitudinal (Figura 9). El elemento intencional o de previsible comportamiento a futuro refleja que el $60 \%$ de los encuestados estaría dispuesto a repetir la visita. Si se relaciona esta afirmación con las opiniones de los visitantes vinculados a la satisfacción, se destaca que los motivos que llevarían a elegir este destino por segunda vez son diversos, siendo la intención de recorrer y visitar todos los sitios de visita que desean', 'estar más tiempo para disfrutar del paisaje' y 'la belleza del lugar', e incluso por su significado simbólico, algunos de los más mencionados.

Figura 9. Intención por volver a visitar el destino y satisfacción alcanzada

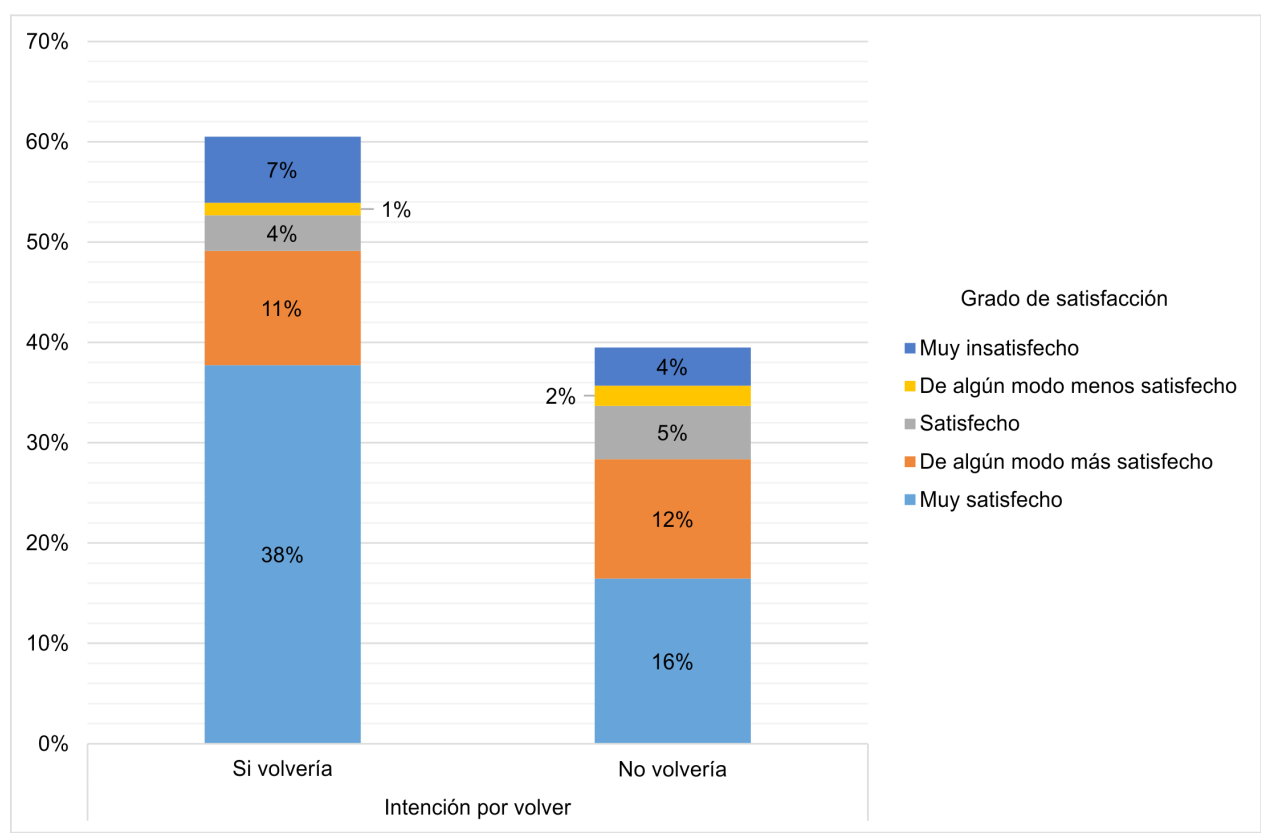

Fuente: elaboración personal con base en las temporadas de análisis 2015/2016, 2016/2017 y 2017/2018 
La respuesta negativa referida a la intención por repetir la visita, si bien refleja un valor menor en relación a la mirada positiva, resulta de interés para ser analizada si consideramos que el $40 \%$ de los cruceristas la eligió. Sin embargo, cuando se profundiza sobre la opinión de los cruceristas es posible destacar que el 16\% aseguró estar muy satisfecho con la misma. Esta contradicción entre el grado de satisfacción y la negativa de repetir el destino podría llamar la atención, sin embargo, una de las características que refleja el turismo de cruceros es que los destinos forman parte de un paquete mayor $y$, en ocasiones, es en el conjunto del itinerario sobre el cual se decide si se repetirá el viaje o no.

El turismo como un agente multiplicador (Ruiz Quesada y Parada Gutierrez, 2013) requiere de la satisfacción de las expectativas generadas por los visitantes para que el mismo actúe retroalimentando esta actividad. La recomendación expresa implícitamente si la experiencia vivida durante la visita satisfizo las expectativas generadas. La consecución de un viaje está cargada de expectativas que buscan completar y generar satisfacción, si la misma no es adquirida, difícilmente sea recomendada.

La respuesta más elegida corresponde a la intención por recomendar el destino y, además, a medida que el grado de satisfacción es mayor, aumenta también el porcentaje de cruceristas que recomendarían el destino. En este sentido, el $51 \%$ de los encuestados que afirmó estar muy satisfecho con la visita recomendaría el destino. Las razones por las cuales lo harían son muchas, pero entre las que más se destacan están 'su beIleza paisajística', 'la esencia del fin del mundo', 'la tranquilidad' y 'la naturaleza'. Expresiones que fueron también sumamente valoradas al momento de describir la localidad.

El porcentaje de respuestas que optaron por recomendar el destino, a pesar de no haber quedado satisfechos con la visita es considerablemente bajo, sin embargo, resulta interesante analizar qué argumentos manifestaron ante esta afirmación. Se destacan mayormente expresiones positivas relacionadas con Ushuaia, siendo los argumentos negativos asociados más al tiempo de visita que a las características per se del destino. Las afirmaciones aquí representadas permiten reflexionar al interior del comportamiento de los cruceristas, planteando cómo la experiencia si bien responde a un colectivo social, depende también y fuertemente de la subjetividad propia de cada individuo, de sus representaciones y actitudes ante el destino.

La última pregunta corresponde a la satisfacción del gasto realizado. Esta variable, de carácter económica, se plantea en relación a la mirada que tienen los cruceristas sobre el destino (Figura 10). El mayor número de respuestas afirman que el gasto que realizaron fue el esperado, generando una mirada neutral en relación al mismo, sin embargo, si se agrupan y analizan los valores extremos se observa que el $32 \%$ de los cruceristas acuerdan haber realizado un gasto superior al esperado y solo el $10 \%$ afirma que el mismo fue menor de lo que tenían pensado.

A pesar de las diferencias sobre la opinión del gasto realizado, en todos los casos es mayor la afirmación que argumenta haber quedado muy satisfecho con la visita. De los encuestados que respondieron haber gastado lo esperado (45\%), el 23\% aseguró estar muy satisfecho con Ushuaia como destino de cruceros. Asimismo quienes afirmaron no estar conformes con el gasto, expresan que la satisfacción fue alta, mientras que, aquellos que prefirieron no responder en relación a la satisfacción del gasto, sí expresan que la visita alcanzó, en su mayoría, la satisfacción esperada.

Junto con la satisfacción se indagó el gasto realizado en las excursiones, la compra de souvenirs, los restaurantes ${ }^{6}$ y otros. La información fue solicitada en la moneda del país de cada encuestado y luego fueron convertidos al dólar estadounidense como moneda de referencia ${ }^{7} y$ agrupados para realizar una lectura más clara.

6 Incluye en esta opción las confiterías y cualquier local comercial de comidas.

7 Se toma como fecha para pautar el dólar de referencia el $31 / 03 / 2018$, correspondiente al último mes de la última temporada considerada para la investigación. 
No fue sencillo indagar en relación al gasto que los visitantes realizan, ya que el alto número de respuestas correspondientes a Ns/Nc demuestra la resistencia de los cruceristas por brindar esa información. Sin embargo, es posible hacer mención a la concentración de los mayores gastos.

En términos generales los menores gastos se vieron reflejados en los souvenirs, que concentra el mayor porcentaje de respuestas en la opción entre U\$S 0-50, seguido por el ítem restaurantes, que también fue elegido en su mayoría bajo esta opción. Para el caso de las excursiones, el mayor porcentaje de gastos se ubicó en el rango que corresponde a U\$S 151300 , respuesta que concuerda con el ítem que es analizado. En general, las excursiones son ofrecidas a bordo del crucero garantizando que las mismas se desarrollen en tiempo y forma. Es común que los cruceristas opten por realizar las actividades pautándolas previamente en el buque, no obstante, al elegir esta opción el valor que deben pagar es mayor al que se ofrece bajo el carácter de excursiones regulares si las contratan en el destino. No todas las excursiones tienen el mismo valor, estas varían según los sitios que se visiten, a pesar de ello se observa que es considerablemente menor el porcentaje que corresponde al valor más alto, con una mayor elección de las excursiones que tienen un valor no mayor a los U\$S 300 .

Figura 10. Grado de satisfacción de la visita y satisfacción del gasto realizado

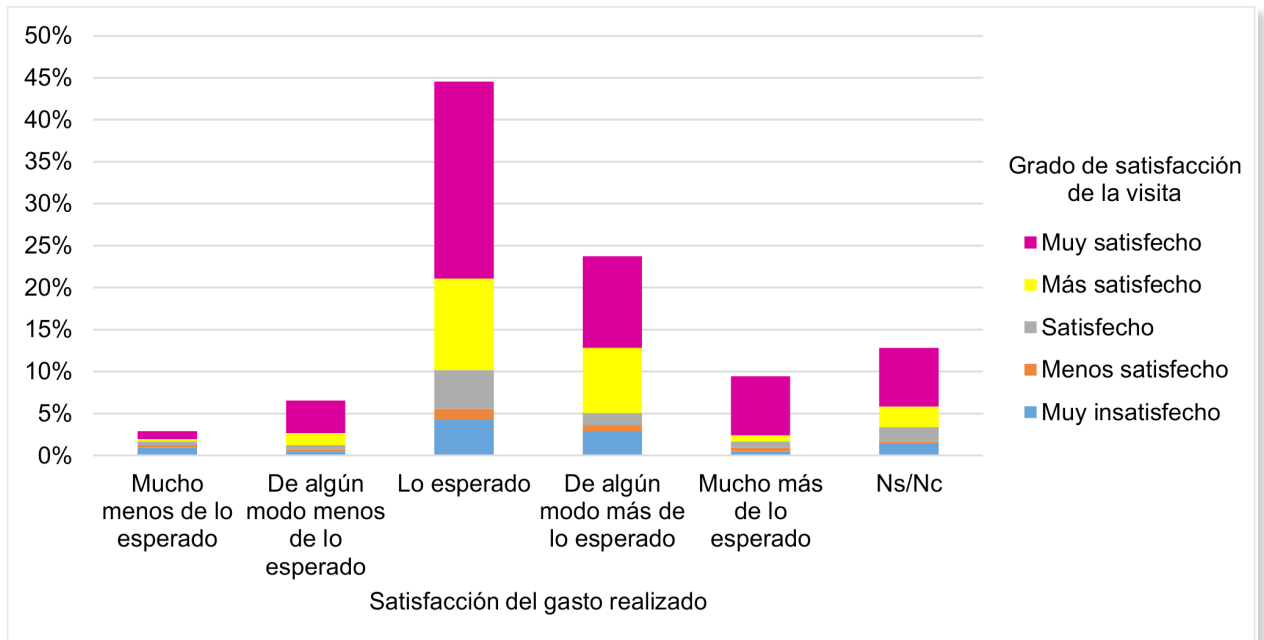

Fuente: elaboración personal con base en las temporadas de análisis 2015/2016, 2016/2017 y 2017/2018

\section{CONSIDERACIONES FINALES}

El turismo de cruceros es planteado como una actividad dinámica y cambiante, atravesado por la competitividad del mercado y las exigencias de la demanda. La producción turística es resultado de diferentes formas de apropiación y consolidación del territorio, los hábitos de consumo y las actividades que realizan los visitantes durante su estadía son algunas de esas formas de apropiación. Son múltiples las manifestaciones turísticas que se yuxtaponen en el territorio, sin embargo, es indiscutido que para que el mismo adquiera una dimensión turística debe hacer efectivo las diferentes capacidades territoriales que posee y reconocer el papel central que tiene la subjetividad como factor para la motivación de la práctica turística. A través de la experiencia se caracterizan las dimensiones materiales y subjetivas que intervienen en el territorio desde la mirada del visitante y permite entender qué valoraciones revisten y potencian al territorio y sobre qué aspectos debe concentrarse la localidad para poder proponer al turismo de cruceros como una posibilidad de potenciar sus capacidades territoriales.

El estudio evidencia que las motivaciones para tomar un crucero están íntimamente rela- 
cionadas con conocer el sur de Sudamérica y la Patagonia, y se rescata su particularidad espacial desde la mirada simbólica que el visitante tiene. Sumado a ello, los resultados apuntan a la importancia asignada a los paisajes que caracterizan a los puertos de destino, así como también los atractivos que poseen. Las motivaciones transcienden al comportamiento previo e influyen en la percepción durante la visita y en su evaluación post-consumo otorgándole un valor diferente a cada destino del itinerario. Son el primer paso para comprender el rol que juega Ushuaia como destino de cruceros y qué posición ocupa dentro de la experiencia de los visitantes. De esta manera, la imagen percibida de Ushuaia está relacionada con la belleza del paisaje, la sensación de un destino agradable y un lugar seguro y único en el itinerario, factores que le otorgan gran valor al lugar. Todas estas declaraciones están altamente relacionadas con los juicios de valor o preferencias que realizaron los propios visitantes, donde la consideración de los elementos del paisaje y las representaciones del destino tales como la idea de naturaleza y de 'fin del mundo' resultaron las opiniones más utilizadas para describirlo.

La satisfacción es también un importante

\section{AGRADECIMIENTOS}

Las autoras desean agradecer la colaboración a las agencias de viajes Tolkeyen y Rumbo Sur; Museo del Fin del Mundo; Claudio de Souza Bispo; Néstor Nehuelhual; Esteban Proz, Celeste Aguilar, Andrea Desconsi, Pablo Camba y Paola

\section{REFERENCIAS}

Almirón, A.V. (2004). Turismo y espacio. Aportes para otra geografía del turismo. GEOUSP Espaço e Tempo, 16, 166-180.

Andriotis, K. y George, A. (2010). Cruise Visitors Experience in a Mediterranean port of call. International Journal of Tourism Research, (12), 390-404.

Blanco, J. (2007). Las geografías de las redes. En M.V. Fernández Caso, R. Bertoncello, J. Blanco, P.J. Ciccolella y C. Natenzon (Eds.) Geogra- factor en el análisis de la experiencia. Los resultados sugieren que, aunque el mayor porcentaje de los encuestados afirmó obtener alto nivel de satisfacción, en algunos casos también se refirieron a que la satisfacción adquirida no fue la esperada, siendo el tiempo de visita uno de los factores más mencionados como condicionante de esta decisión. Tener una buena experiencia en un puerto determinado puede influir en la probabilidad de una visita de regreso, así como en la recomendación a otros. Por ello, satisfacer las expectativas del visitante durante su visita en la ciudad, con el fin de ofrecer experiencias más positivas que otros puertos, afianza la permanencia de los mismos dentro de los itinerarios de las líneas de crucero.

Entender mejor la experiencia de los cruceristas que visitan la ciudad de Ushuaia les brinda a los responsables de la toma de decisiones, en el sector turístico local, ideas sobre cómo mejorar el producto para el beneficio del destino y la satisfacción de los visitantes. Establecer las características de la experiencia y la capacidad del destino para satisfacer las motivaciones que dan lugar a la demanda resulta fundamental para la fortalecer la actividad turística y optimizar los recursos empleados para su desarrollo.

Rincón por su cooperación para la obtención de encuestas. A la docente-investigadora la Esp. Marie Jensen por la lectura del manuscrito y sus valiosos aportes y a los árbitros de esta contribución por sus oportunas sugerencias.

fía y territorios en transformación. Buenos Aires: NOVEDUC.

Benedetti, A. (2011) Territorio: Concepto de la geografía contemporánea (pp.11-82). En P. Souto (Coord.) Territorio, lugar, paisaje. Prácticas y conceptos básicos en geografía. Buenos Aires: Editorial de la Facultad de Filosofía y Letras. UBA. Bertoncello, R. (2006). Los imaginarios de espacios distantes a partir del turismo (pp. 205- 
222). En A. Lindón y D. Hiernaux (Eds.) Geografías de lo imaginario. Madrid: ANTROPOS.

Bertoncello, R. y Troncoso, C. (2014). La ciudad como objeto de deseo turístico renovación urbana cultural y turismo en Buenos Aires y Salta. Gran Tour: Revista de Investigaciones Turísticas, (9), 4-26.

Boisier, S. (1997). El vuelo de una cometa. Una metáfora para una teoría del desarrollo territorial. Revista EURE, 23(69), 7-29.

Boisier, S. (1998). Post-scriptum sobre desarroIlo regional: Modelos reales y modelos mentales. Revista EURE, 24(72), 3-38. Recuperado de http://www.redalyc.org/pdf/196/19607203.pdf

Boisier, S. (2005). Hay espacio para el desarrollo local en la globalización. Revista de la Cepal, (86), 1-22.

Brida, J.G.; Zapata Aguirre, S. y Giraldo Velásquez, C.M. (2010). Análisis del perfil y satisfacción de los pasajeros de cruceros que visitan el puerto de Cartagena de Indias. TUR y $D E S$. Revista de investigación en turismo y desarrollo local, 3(8). Recuperado de http://www.eumed. net/rev/turydes/08/bav.htm

Bustos Cara, R. (2001). Identidad, turismo y territorios locales. La permanente construcción de valores territoriales. Aportes y Transferencias, 5(1), 11-28.

Butler, M. (2008). Turismo de cruceros. Situación actual y tendencias. España: Organización mundial del turismo.

Callizo Soneiro, J. (1991). Aproximación a la geografía del turismo. Madrid: Síntesis.

Cammarata, E.B. (2006). El turismo como práctica social y su papel en la apropiación y consolidación del territorio (pp. 352-366). En A.I. Geraiges de Lemos, M. Arroyo y M.L. Silveira (Eds.) América Latina: cidade, campo e turismo. San Pablo: CLACSO. Recuperado de http:// bibliotecavirtual.clacso.org.ar/ar/libros/edicion/lemos/20cammar.pdf

Campos Martínez, S. y Yague Guillen, M.J. (2007). Efectos de las promociones en precios sobre la satisfacción del turista: Examen de la relación entre precio y la satisfacción. PASOS. Revista de turismo y patrimonio cultural, 5(2), 139-148.

CLIA (2015). (Informe de impacto del turismo de cruceros 2015). Cruise industry outlook. Cruising to New Horizons and Offering Travelers More. Recuperado de https://www.cliadeutschland. de/pdf/2015/21_Grafik_Outlook2016.pd$f ? m=1449055034$

Dann, G.M. (1981). Tourist motivation. An appraisal. Annals of Tourism Research, VIII(2), 187-219.

Daverio, M.E.; Mosti, P.; Malmierca, L.; Arcos, A. y Arias, M. (2007). Relaciones entre motivaciones de visita, expectativas y percepción de congestionamiento y las actividades que realizan los visitantes en el Parque Nacional Tierra del Fuego, Argentina. Jornadas Nacionales de Investigación y Acción en Turismo. Posadas: Universidad Nacional de Misiones.

Daverio, M.E., Jensen, M. y Vereda, M. (2009). Análisis exploratorio sobre la potencialidad de las relaciones buque-destino de Ushuaia, como puerto base y de escala de cruceros turísticos (Informe de Investigación). Ushuaia: Universidad Nacional de la Patagonia San Juan Bosco.

Estepa Montero, M. (2013). Los puertos del Estado y el tráfico de cruceros marítimos. Anuario Jurídico y Económico Escurialense, XLVI, 325-44.

Esteve Pérez, J.; García Sánchez, A. y Romero Gutiérrez, E.J. (2016). Dinamismo del turismo de cruceros en el Mediterráneo Occidental. $X I X$ Congreso AECIT. Tiempos de cambio en el turismo. Adeje. Tenerife.

Fernández, M.; García, M. y Picos, A. (2010). Motivación, satisfacción y lealtad en el turismo: el caso de un destino de interior. Revista Electrónica de Motivación y Emoción, 13(35-36).

Ghisolfo, F. (2001). Cruceros turísticos en América del Sur: Nuevas oportunidades y desafíos. CEPAL. Boletín FAL, (176), 1-6.

Gnoth, J. (1997). Tourism motivation and expectation formation. Annals of Tourism Research, 24(2), 283-304. DOI https://doi.org/10.1016/ s0160-7383(97)80002-3

InFueTur. (2015). Informe de Cruceros turísticos. (Puerto de Ushuaia. Año 2014 y temporada 
2014/2015). Recuperado de https://cdn.tierradelfuego.org.ar/descargas/cruceros/Informe_de_Cruceros-2014-2015.pdf

InFueTur. (2018). Principales indicadores de turismo temporada estival 2017-2018. Tierra del Fuego. Recuperado de https://cdn.tierradelfuego.org.ar/ descargas/informes-de-coyuntura-turistica/ Informe_Temporada_estival_2017-2018.pdf

Jensen, M. y Daverio, M.E. (2004). Los cruceros turísticos en Ushuaia, Argentina. Relaciones Buque-Destino. Aportes y Transferencias, 8(1), 89-112.

Jensen, M. y Vereda, M. (2016). La competitividad de Ushuaia como puerta de entrada marítima del turismo antártico. Posibilidades para el desarrollo local a partir de la especialización del destino. Informe Final PIDUNTDF A 06/2016, UNTDF: Ushuaia.

Lash, S. y Urry, J. (1998). Economía de signos y espacio. Sobre el capitalismo de la posorganización. Buenos Aires: Amorrortu.

Lobato Corrêa, R. (1995). Espaço: um conceito-chave da Geografia (pp. 1-16). En I. Elias de Castro, P.C. da Costa Gomes y R.L. Corrêa (Eds.) Geografia: conceitos e temas. Rio de Janeiro: Bertrand.

Mannell, R.C. e Iso-Ahola, S. (1987). Psychological nature of leisure and tourism experience. Annals of Tourism Research, 14(3), 314-331.

Martínez, C.I. (2012). Perspectivas del turismo de cruceros en Argentina en el marco de las tendencias mundiales. Notas en Turismo y Economía, (III), 44-71.

Montañez Gómez, G. y Delgado Mahecha, O. (1998). Espacio, Territorio y Región: Conceptos Básicos Para Un Proyecto Nacional. Cuadernos de Geografía, VII(1-2), 120-135.

Nogué i Font, J. (1992). Turismo, percepción del paisaje y planificación del territorio. Estudios Turísticos, (115), 45-54.

Nogué, J. y Vela, J. de S.E. (2011). La dimensión comunicativa del paisaje. Una propuesta teórica y aplicada. Revista de Geografía Norte Grande, 49, 25-43.

Oliveira, B. (2011). Determinantes de la satisfacción del turista. Un estudio en la ciudad de
Guarujá-Brasil. Estudios y Perspectivas en Turismo, 20, 229-242.

Ortega Valcárcel, J. (2000). Los horizontes de la geografía. Teoría de la geografía. Barcelona: Editorial Ariel S. A.

Palmero, F. (2008). El proceso de motivación (pp. 1-26). En F. Palmero y F. Martínez Sánchez (Coords.) Motivación y emoción. Madrid: McGraw-Hill.

Pillet Capdepón, F. (2004). La Geografía y las distintas acepciones del Espacio Geográfico. Investigaciones geográficas, (34), 141-154.

Rodrigue, J.P. y Notteboom, T. (2013). The geography of cruises: Itineraries, not destinations. Applied Geography, 38, 31-42.

Rojas López, J.J. y Gómez Acosta, E.C. (2010). Tiempos del pensamiento geográfico. Venezuela: Archivo arquidiocesano de Mérida-AAM.

Ruiz Quesada, S.C. y Parada Gutiérrez, O. (2013). El turismo de crucero: Una alternativa para el desarrollo local. Investigación y saberes, II(2), 49-58.

Santos, M. (1977). Society and Space: Social formation as theory and method. Antipode, Worcester, 9(1), 3-13.

Santos, M. (1986). Espacio y Método. Cuadernos críticos de geografía humana, (65), 1-43.

Santos, M. (2000). La naturaleza del espacio. Técnica y tiempo. Razón y emoción. Barcelona: Editorial Ariel S. A.

Santos Solla, X. (2008). Paisaje e identidad en la promoción de la imagen de los destinos turísticos (pp. 196-206). En J. Ivars Baidal y F. Vera Rebollo (Eds.) Espacios turísticos, mercantilización paisaje e identidad. Alicante: Agua Clara.

Sharpley, R y Stone, P. (2011). Tourist experience. Contemporary perspective. Nueva York: Routledge. Sheller, M. y Urry, J. (2006). The new mobilities paradigm. Environment and Planning A, 38, 207226. doi: $10.1068 / \mathrm{a} 37268$.

Silveira, M.L. (2011). Territorio y ciudadanía: reflexiones en tiempos de globalización. Uni-pluri/versidad, 11(3), 1-23.

Tamayo Tamayo, M. (2003). El proceso de la investigación científica. Incluye evaluación y administración 
de proyectos de investigación. Ciudad de México: Limusa Noriega Editores.

Troncoso, C.A. (2008). Creando un lugar turístico y patrimonial: Las transformaciones en la Quebrada de Humahuaca a partir de los procesos de construcción de atractividad turística y patrimonialización. Tesis doctoral. Universidad de Buenos Aires.

Tuan, Y.-F. (2001). Space and place. The perspective of experience. Minneapolis: University of Minnesota Press.

Uriely, N. (2005). The tourist experience. Conceptual developments. Annals of Tourism Research, 32(1), 199-216. DOI https://doi.org/10.1016/j.annals.2004.07.008

Vereda, M. (2007). Análisis de la relación de Ushuaia con el turismo Antártico desde su rol de puerta de entrada marítima. Una aproximación desde los indicadores socio-económicos para la temporada 2005/2006. VIII Jornadas Nacionales y II Simposio Internacional de Investigación - Acción en Turismo. Posadas: Universidad Nacional de Misiones.

Vereda, M. y Jensen, M. (2014). Territorios remotos del turismo: la articulación de espacios turísticos asociados en el atlántico sur meri- dional. VI Congreso Latinoamericano de Investigación Turística. Neuquén: Universidad Nacional del Comahue.

Vereda, M. y Jensen, M. (2015). Comportamiento del turismo antártico que operó en el puerto de Ushuaia. Temporadas 2008/2009 a 2014/2015. VII Simposio Internacional y XII Jornadas Nacionales de Investigación - Acción en Turismo. Neuquén: Universidad Nacional del Comahue. Vereda, M. (2016). Antarctica in the mind of visitors. Representations of a remote destination (pp. 1-19). En M. Schillat, M. Jensen, M. Vereda, R.A. Sanchez y R. Roura (Eds.) Tourism in Antarctica. A multidisciplinary view on new activities carried out on the White Continent. Cham: Springer. DOI 10.1007/978-3-319-39914-0_1.

Wood, R. (2000). Caribbean cruise tourism: Globalization at sea. Annals of Tourism Research, 27(2), 345-370.

Wood, R. (2004). Cruise ships: Deterritorialized destinations. En L. Lumsdon y S.J. Page (Eds.) Tourism and Transport. Issues and agenda for the new millennium). Amsterdam. Boston. Heidelberg. London. New York. Oxford Paris. San Diego. San Francisco. Singapore. Sydney. Tokyo: Elsevier.

\section{Anexo 1. Modelo de enCUeSta APLICADA}

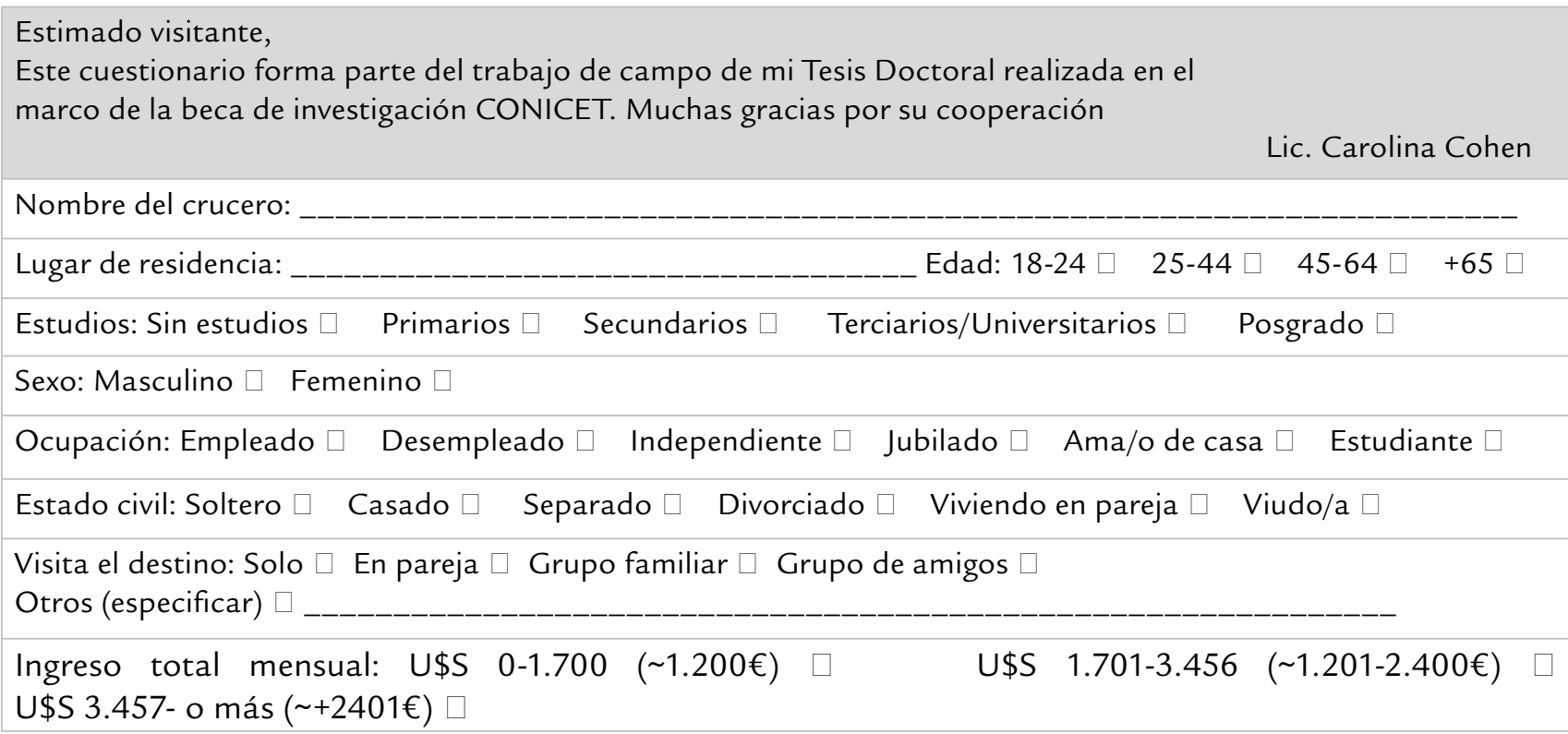


1) ¿Por qué decidió tomar este crucero? Indique su respuesta según orden de importancia, seleccionando hasta tres opciones, siendo:

1 = motivación poco relevante, 2 = motivación relevante, 3 = motivación muy relevante

\begin{tabular}{|c|c|}
\hline Por recomendación de otros & Para conocer la Patagonia \\
\hline Para conocer el sur de Sudamérica & Para navegar en crucero \\
\hline Por el paisaje & Por atracción de los puertos de visita \\
\hline Por la flora y fauna de los puertos de visita & Por la historia y los museos de los puertos de visita \\
\hline
\end{tabular}

2) A partir de su experiencia en Ushuaia, por favor manifieste su grado de acuerdo en relación con las siguientes afirmaciones, siendo:

1 = totalmente en desacuerdo, 2 = en desacuerdo, 3 = neutral, 4 = de acuerdo, 5 = totalmente de acuerdo

\begin{tabular}{|l|l|l|l|l|l|}
\hline \multicolumn{1}{|c|}{ Afirmaciones sobre Ushuaia } & \multicolumn{4}{c|}{ Valoraciones } \\
\hline Es un destino agradable & 1 & 2 & 3 & 4 & 5 \\
\hline Es un destino seguro para visitar & 1 & 2 & 3 & 4 & 5 \\
\hline Es un destino turístico relajante & 1 & 2 & 3 & 4 & 5 \\
\hline Es un destino único en relación con el itinerario & 1 & 2 & 3 & 4 & 5 \\
\hline Dispone de atractivos culturales relevantes para visitar & 1 & 2 & 3 & 4 & 5 \\
\hline Posee belleza paisajística & 1 & 2 & 3 & 4 & 5 \\
\hline Posee gran diversidad de atractivos turísticos & 1 & 2 & 3 & 4 & 5 \\
\hline Ofrece muchas oportunidades para el turismo aventura & 1 & 2 & 3 & 4 & 5 \\
\hline
\end{tabular}

3) Por favor, mencione las tres características que a su criterio identifican a Ushuaia

4) Por favor, indique el grado de satisfacción de su visita a Ushuaia, marque una de las siguientes opciones

\begin{tabular}{|l|l|}
\hline Muy insatisfecho \\
\hline De algún modo menos satisfecho \\
\hline Satisfecho \\
\hline De algún modo más satisfecho \\
\hline Muy satisfecho \\
\hline
\end{tabular}

¿Por qué eligió esa opción? 
5) ¿Le gustaría que el crucero permaneciera más tiempo en Ushuaia?

Si $\quad$ No

6) En caso de ser su respuesta afirmativa, ¿Cuánto tiempo más le gustaría dedicar a Ushuaia?

\begin{tabular}{|c|c|c|c|}
\hline Un día & $\begin{array}{l}\text { Un día y } \\
\text { una noche }\end{array}$ & Dos días & 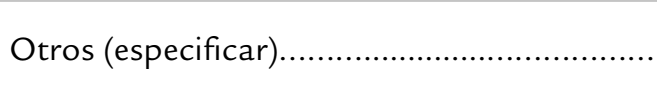 \\
\hline
\end{tabular}

7) ¿Volvería a visitar el destino?

\begin{tabular}{|l|l|l}
\hline Sí, probablemente voy a volver & No, probablemente no voy a volver
\end{tabular}

8) ¿Recomendaría visitar este destino en crucero?

\begin{tabular}{|c|c|c|}
\hline Sí & No & ¿Por qué? \\
\hline
\end{tabular}

9) ¿Podría indicar en su moneda el gasto que realizó, por pasajero, en Ushuaia en función de los siguientes ítems?

\begin{tabular}{|c|c|c|c|}
\hline Excursiones & & Compra de souvenirs & \\
\hline Restaurantes/confiterías & $\ldots \ldots \ldots \ldots \ldots$ & 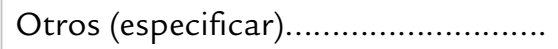 & .................... \\
\hline
\end{tabular}

10) Por favor, indique el grado de satisfacción en el gasto realizado en Ushuaia:

\begin{tabular}{|l|l|}
\hline Mucho menos de lo esperado \\
\hline De algún modo menos de lo esperado \\
\hline Lo esperado \\
\hline De algún modo más de lo esperado \\
\hline Mucho más de lo esperado \\
\hline
\end{tabular}

11) ¿Le interesaría conocer otros puertos de cruceros ubicados en la costa patagónica?

\begin{tabular}{|l|l|l|}
\hline Si & No &
\end{tabular}


12) En caso afirmativo, por favor indique su grado de interés por conocer los siguientes atractivos, siendo:

1 = nada interesante, 2 = de algún modo poco interesante, 3 = neutral, 4 =de algún modo más interesante, 5 = muy interesante

\begin{tabular}{|c|c|c|c|c|c|}
\hline Atractivos & \multicolumn{5}{|c|}{ Valoración } \\
\hline Cuevas de arte rupestre & 1 & 2 & 3 & 4 & 5 \\
\hline Yacimientos arqueológicos & 1 & 2 & 3 & 4 & 5 \\
\hline Yacimientos paleontológicos (fósiles) & 1 & 2 & 3 & 4 & 5 \\
\hline Afloramientos rocosos significativos & 1 & 2 & 3 & 4 & 5 \\
\hline Avifauna (pingüinos, cormoranes, carpinteros...) & 1 & 2 & 3 & 4 & 5 \\
\hline Fauna marina (ballenas, toninas, lobos marinos...) & 1 & 2 & 3 & 4 & 5 \\
\hline Rías & 1 & 2 & 3 & 4 & 5 \\
\hline Humedales & 1 & 2 & 3 & 4 & 5 \\
\hline Bosque petrificado & 1 & 2 & 3 & 4 & 5 \\
\hline Áreas protegidas & 1 & 2 & 3 & 4 & 5 \\
\hline Playas (sol y baños de mar) & 1 & 2 & 3 & 4 & 5 \\
\hline Montaña/Sierras & 1 & 2 & 3 & 4 & 5 \\
\hline Estepa patagónica & 1 & 2 & 3 & 4 & 5 \\
\hline Bosque subantártico & 1 & 2 & 3 & 4 & 5 \\
\hline Museos & 1 & 2 & 3 & 4 & 5 \\
\hline Lugares visitados y descriptos por Charles Darwin y otros exploradores & 1 & 2 & 3 & 4 & 5 \\
\hline Casinos & 1 & 2 & 3 & 4 & 5 \\
\hline Vida nocturna (teatros, pubs, baile...) & 1 & 2 & 3 & 4 & 5 \\
\hline Sitios históricos & 1 & 2 & 3 & 4 & 5 \\
\hline Faros & 1 & 2 & 3 & 4 & 5 \\
\hline Comidas típicas & 1 & 2 & 3 & 4 & 5 \\
\hline Shows & 1 & 2 & 3 & 4 & 5 \\
\hline Estancias patagónicas & 1 & 2 & 3 & 4 & 5 \\
\hline
\end{tabular}

13) ¿Qué actividades le interesaría realizar en un destino visitado en crucero? Seleccione hasta tres actividades según el orden de importancia que le asigna, siendo:

1 = nada interesante, 2 = interesante, 3 = muy interesante

\begin{tabular}{|c|c|c|c|}
\hline Kayakismo & Surf & Buceo & $4 \times 4$ \\
\hline Trekking & Actividades rurales & Parapente & Baños de sol y mar \\
\hline Kitesurf & Cabalgatas & Pesca deportiva & Bicicleta de montaña \\
\hline Escalada & \multicolumn{3}{|r|}{ …………… } \\
\hline
\end{tabular}


14) ¿Qué servicios considera que debe brindar un destino de cruceros? Indique su respuesta según orden de importancia, siendo:

1 = servicio poco relevante, 2 = servicio relevante, 3 = servicio muy relevante

\begin{tabular}{|c|c|}
\hline Diversidad en oferta gastronómica & Variedad de excursiones / actividades \\
\hline Facilidad de acceso a los atractivos & Medios de transporte \\
\hline Centros comerciales & Otros (especifique).. \\
\hline
\end{tabular}

15) Cualquier comentario que desee realizar será bienvenido:

Muchas gracias por su gran cooperación

Carolina Cohen es Licenciada en Geografía. Becaria Doctoral del Consejo Nacional de Investigaciones Científicas y Técnicas CONICET. Docente investigadora de la Carrera Licenciatura en Turismo, Instituto de Desarrollo Económico e Innovación, UNTDF. Forma parte del equipo de investigación "Turismo antártico". Participa activamente en encuentro académicos nacionales e internacionales y ha publicado en diferentes revistas sobre temáticas referidas a turismo de cruceros y geografía. Instituto de DesarroIlo Económico e Innovación. Universidad Nacional de Tierra del Fuego, Antártida e Islas del Atlántico Sur UNTDF. Yrigoyen 879, (9410) Ushuaia, Tierra del Fuego, Argentina, ccohen@untdf.edu.ar

Marisol Vereda es Licenciada en Turismo. Especialista en Educación Superior. Magister en Gestión Pública del Turismo. Doctora en Geografía. Docente investigadora Carrera Licenciatura en Turismo, Instituto de Desarrollo Económico e Innovación, UNTDF. Dirige el equipo de investigación "Turismo antártico", posee vasta experiencia en el ámbito académico. Forma parte de redes académicas nacionales e internacionales, participa activamente en encuentros académicos y ha publicado en diferentes revistas nacionales e internacionales. Instituto de Desarrollo Económico e Innovación. Universidad Nacional de Tierra del Fuego, Antártida e Islas del Atlántico Sur UNTDF. Yrigoyen 879, (9410) Ushuaia, Tierra del Fuego, Argentina, mvereda@untdf.edu.ar 